\title{
2015 Status Report on Major Defence Equipment Procurements
}

by David Perry December, 2015

CANADIAN Global AFFAIRS INSTITUTE INSTITUT CANADIEN DES AFFAIRES MONDIALES

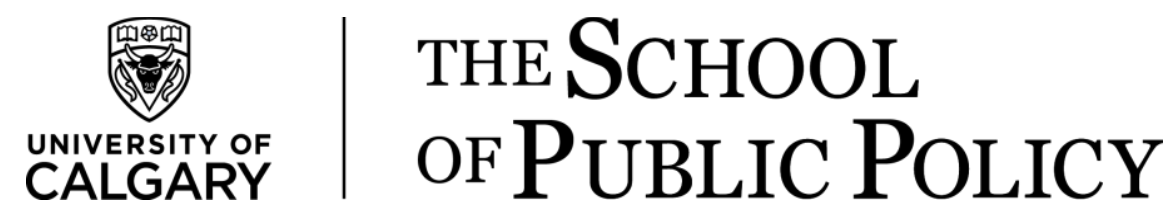

\section{UNIVERSITY OF CALGARY}

CENTRE FOR MILITARY AND STRATEGIC STUDIES 


\section{POLICY PAPER}

\section{STATUS REPORT ON MAJOR DEFENCE EQUIPMENT PROCUREMENTS*}

by David Perry

Senior Analyst, CGAI

December, 2015 


\section{$\triangleright$ Executive Summary}

Federal elections may be good for democracy, but the campaigns - particularly the lengthy one recently held in Canada - can be crippling for plans to better arm our military. Just before the election was called, there were public signs of important progress being made in what has long been a frustratingly slow and bureaucratically complex procurement process. But then the campaign left the Department of National Defence and other federal departments unable to secure approvals from either a defence minister or the Treasury Board, until the election ended and the new prime minister appointed the current cabinet.

There had already been upheaval prior to that: In the first seven months of 2015, the three senior leaders at the Canadian Forces and the Defence Department (including the minister) had been replaced, along with many other people critical to the procurement process. In addition, there had been changes in the Public Works Department and the Defence Procurement Strategy Secretariat.

Frustrating and disappointing delays have long been a matter of course in Canada's defence procurement process. In 2014/15, the number of ministerial or Treasury Board approvals to allow projects to proceed was half of that in 2009/10. Yet the demand for approvals has not abated.

In addition to the turnover of key figures involved in the procurement and approval process, delays have come from a number of major steps added to the process, making an already lengthy and complex system even more so. To be sure, these steps were added in the pursuit of improved financial management and project management, with the aim of addressing longstanding problems. But it will take years to see if those objectives have been realized.

An irony here is that the budget for military procurement has increased. Between 2004 and 2009, the Defence Department's procurement budget nearly doubled. But the funding was never matched by the capacity to manage it. In 2003, the Material Group had a ratio of 2,600 staff for every \$1 billion in procurement funds. By 2009, the ratio had become 1,800 staff for every $\$ 1$ billion in procurement funds. Since then, the ratio has only gotten substantially worse.

New systems now require extensive analysis to determine if a more intensive Treasury Board review is required. A recently created panel designed to provide a "third-party challenge function" on requirements for major procurements has created some confusion among officials as to what documentation they should be producing to support procurement initiatives. And the panel's terms of reference are extensive, ranging from evaluating a project's alignment with government policy and the level of its fit with allies' capabilities, to the role of Canadian suppliers and the anticipated support concept.

Still, there are some indications that changes enacted in 2014 to the procurement process may eventually help mitigate delays in the future. There are continual improvements being made to the way the Defence Department conducts project costing as well as how the Treasury Board Secretariat evaluates the costs, which will help improve the compatibility between estimates and newly introduced frameworks. New methods of better prioritizing projects have also been introduced. And there are plans underway intended to reduce the time involved in the department's internal approval processes. For now, however, these attempts at improvement have been focused on the lower-dollar-figure approvals done by the minister. It remains to be seen if, first, they work, and secondly, if they can then be used to facilitate Treasury Board approvals, as well.

\footnotetext{
* This research was financially supported by the Government of Canada via a partnership with Western Economic Diversification.
} 


\title{
Rapport de situation 2015 sur les acquisitions majeures de matériel de défense*
}

\author{
David Perry
}

\section{Sommaire}

Les élections fédérales sont sans doute bonnes pour la démocratie mais les campagnes, en particulier la longue campagne récemment menée au Canada, peuvent paralyser les plans pour mieux armer nos forces militaires. Juste avant l'annonce des élections, il y avait des signes visibles que d'importants progrès étaient réalisés dans ce qui a longtemps été un processus d'approvisionnement excessivement lent et bureaucratiquement complexe. La campagne a toutefois laissé le ministère de la Défense nationale et d'autres ministères fédéraux dans l'incapacité d'obtenir des approbations d'un ministre de la Défense ou du Conseil du Trésor jusqu'à la fin des élections et à la nomination du cabinet actuel par le nouveau premier ministre.

Le chaos régnait déjà avant cette période. Au cours des sept premiers mois de 2015, les trois plus hauts dirigeants des Forces canadiennes et du ministère de la Défense (dont le ministre) avaient été remplacés, ainsi que de nombreuses autres personnes essentielles au processus d'approvisionnement. De plus, des changements avaient eu lieu au ministère des Travaux publics et au Secrétariat de la Stratégie d'approvisionnement en matière de défense.

Des retards frustrants et décevants sont depuis longtemps chose courante dans le processus d'approvisionnement en matière de défense. En 2014/15, le nombre d'approbations par le ministère ou le Conseil du Trésor pour permettre l'exécution de projets a été la moitié du nombre en 2009/10. Pourtant, la demande d'approbations n'a pas diminué.

En plus du roulement de personnages importants impliqués dans le processus d'approvisionnement et d'approbation, les retards ont eu comme source l'addition de plusieurs étapes majeures au processus, ce qui a rendu encore plus long et plus complexe un système qui l'était déjà. Bien entendu, ces étapes ont été ajoutées en vue d'améliorer la gestion financière et la gestion des projets, afin de s'attaquer à des problèmes de longue date, mais il faudra des années pour savoir si ces objectifs ont été atteints.

Ironiquement, le budget de l'approvisionnement militaire a augmenté. Entre 2004 et 2009, le budget d'approvisionnement du ministère de la Défense a presque doublé. La capacité de gérer ce financement n'a toutefois jamais été à la hauteur. En 2003, le Groupe des matériels avait un ratio de 2600 employés par tranche de 1 milliard de dollars en fonds d'approvisionnement. En 2009, ce ratio était de 1800 employés par tranche de 1 milliard de dollars en fonds d'approvisionnement. Depuis lors, le ratio n'a fait que diminuer considérablement.

* Cette recherche a été soutenue financièrement en partie par le gouvernement du Canada via Diversification de l'économie de l'Ouest Canada. 
Les nouveaux systèmes ont maintenant besoin d'une analyse exhaustive pour déterminer si un examen plus approfondi par le Conseil du Trésor est nécessaire. Un groupe d'experts récemment créé et conçu pour assurer une « analyse critique indépendante » des exigences pour les approvisionnements majeurs a suscité une certaine confusion parmi les représentants quant à la documentation qu'ils devraient présenter pour appuyer les initiatives du gouvernement. De plus, le mandat de ce groupe d'experts est large, allant de l'évaluation de la conformité d'un projet avec la politique gouvernementale et de son niveau d'adéquation avec les capacités des alliés, jusqu'au rôle des fournisseurs canadiens et au concept du soutien prévu.

Il y a toutefois quelques indications que des changements au processus d'approvisionnement adoptés en 2014 pourraient finir par aider à réduire les retards dans l'avenir. On apporte en continu des améliorations à la manière dont le ministère de la Défense effectue la détermination des coûts des projets, ainsi qu'à la manière dont le Secrétariat du Conseil du Trésor évalue les coûts, ce qui contribuera à rehausser la compatibilité entre les estimations et les cadres nouvellement mis en œuvre. De nouvelles méthodes améliorées de priorisation des projets ont également été mises en place. De plus, il existe des plans en cours conçus pour réduire le temps requis par les processus d'approbation internes du ministère. Pour l'instant toutefois, ces tentatives d'amélioration ont ciblé des approbations de projets de moindre valeur effectuées par le ministère. Il reste à voir, en premier lieu, si elles fonctionnent et, en deuxième lieu, si elles peuvent servir pour faciliter également les approbations par le Conseil du Trésor. 
his report is the third edition of the annual status report on selected major defence
acquisitions. It retains the focus from that of the 2014 edition of providing "a
comprehensive yet concise and readily understandable reference that clearly
states: What major defence acquisition commitments have been made and why; what progress has been made on those acquisitions and what is their current status; and why it may be that stated and actual delivery dates differ." The intent is to provide an informative document that can assist anyone who is interested in tracking progress on military acquisitions. $^{2}$

Two groups of projects were chosen for this edition. Those in Annex 1, summarized below, are from the list of projects included in the Department of National Defence's Report on Plans and Priorities 2015/2016, Status Report on Major Crown Projects. ${ }^{3}$ This list was selected because it is by definition the list of projects that the Department of National Defence (DND) and the Canadian Armed Forces (CAF) identify as the most important projects over the $\$ 100$ million, Major Crown Project threshold. There remains an element of subjectivity in their selection for inclusion in the Status Report by DND, as the projects are chosen based on their assessed importance to the Government of Canada, ${ }^{4}$ but the inclusion of this list in its entirety removes the element of subjectivity from the author of this report in determining which projects to include, and which to not. Of note, this list focuses exclusively on projects for defence equipment, and therefore excludes infrastructure, information management and information technology and contracts for services. The ten projects with a check mark $(\checkmark)$ beside them appeared in the previous iteration of this report.

The projects in Annex 2 are those that appear in both the 2015 and 2014 Defence Acquisition Guide. ${ }^{5}$ This publication arose as part of the 2014 Defence Procurement Strategy in an effort to better inform the defence industry about potential future defence purchases. As many of the projects have not yet received formal approvals, the focus was placed on those projects that the main capability sponsors within DND, the Canadian Army, Royal Canadian Air Force (RCAF) and Royal Canadian Navy (RCN) are actively working on.

These two lists are largely complementary. Although there are some overlap and exceptions, each Annex focuses on projects at different stages in the procurement process, which has five primary stages: Identification; Options Analysis; Definition; Implementation and Close Out.

\footnotetext{
Elinor Sloan. Something Has to Give (Calgary: The Canadian Defence \& Foreign Affairs Institute, The School of Public Policy, University of Calgary, and the Centre for Military and Strategic Studies, University of Calgary, 2014)

2 The first report in this series was David Bercuson, Aaron Plamondon and Ray Szeto, An Opaque Window. (Calgary: Canadian Defence \& Foreign Affairs Institute, 2006).

3 National Defence and the Canadian Armed Forces, Report on Plans and Priorities 2015/2016 (Ottawa: Public Works and Government Services Canada, 2015).

4 Confidential Interview.

5 National Defence and the Canadian Armed Forces, Defence Acquisition Guide 2015, June 25, 2014 http://www.forces.gc.ca/ en/business-defence-acquisition-guide-2015/naval-systems.page, National Defence and the Canadian Armed Forces, Defence Acquisition Guide 2014, June 25, 2014 http:/www.forces.gc.ca/en/business-defence-acquisition-guide/joint-systems.page
} 
According to the 2015 Defence Acquisition Guide, the five stages of the procurement process can be summarized as follows (see Figure 1 as well):

\section{- Stage 1 - Identification.}

- Stage 2 - Options Analysis.

- Stage 3 - Definition.

- Stage 4 - Implementation.

- Stage 5 - Close-Out.

While there have been some significant changes made to the procurement process after 2009, discussed below, much of the process remains the same. It involves, at a minimum, the full Cabinet, the Treasury Board (the subset of Cabinet responsible for financial management), the Treasury Board Secretariat (the bureaucracy that supports the Treasury Board), DND, Public Works and Government Services Canada (the federal department responsible for purchasing defence goods). In the Project Identification stage, a capability deficiency or gap is identified by one of the many project sponsors in the CAF, of which the Army, RCN and RCAF are the three largest. During this stage, the potential risks of addressing the capability deficiency, potential funding sources and the policy coverage are all identified. If the proposal to address the capability deficiency is approved by the Defence Capability Board, it officially becomes a project. These new projects enter the Options Analysis stage, where the Statement of Operational Requirement is developed, and the optimal method to addressing the capability gap is identified. This includes an assessment of the costs and benefits of options, engagements with industry and the identification of the preferred option.

At the end of Options Analysis the project is put forward for Preliminary Project Approval for expenditure authority by either the Minister of National Defence or the Treasury Board. Prior to 2009, whether a project was approved by the Treasury Board or Minister of National Defence, it was determined by the project's estimated costs; those over $\$ 30$ million required the Treasury Board's approval. If Preliminary Project Approval is granted, this marks the transition from determining what should be done to mitigate a deficiency, to determining how the preferred option will be implemented. This approval also means that the project is assigned 'Vote 5' Capital funding, the special financial authorities used when the capital expenditures in a program equal or exceed $\$ 5$ million $^{6}$ - some of which is used to stand up a dedicated project management team, which determines substantive requirements, cost and schedule estimates as well as investigating and mitigating risk. At the end of this process, a project goes forward for Effective Project Approval, to either the Minister of National Defence or the Treasury Board based on the same cost threshold as above. If secured, the project enters the Implementation stage which enables the Department of National Defence to have the contract awarded through Public Works and Government Services Canada. As equipment is delivered, the project eventually reaches an Initial Operational Capability (IOC) which in project management terms is the milestone reached when the capability provided by the project can be used operationally on a sustained basis. The next meaningful milestone is Full Operational Capability (FOC), which is the milestone reached when all project deliverables have been delivered. At that point,

Office of the Auditor General of Canada, Examining Public Spending (Ottawa: Minister of Public Works and Government Services, 2012). 
the project turns into a capability that is managed by the DND organizations responsible for equipment maintenance and sustainment. At that point, the project approving authority will receive a final report during the Close-Out stage of each project. ${ }^{7}$

The projects in Annex 1 are mostly in the latter stages of the procurement process (either Definition or Implementation) whereas the projects in Annex 2 are largely in the earlier stages (Project Identification or Options Analysis). In combination, these two lists provide a comprehensive and objective picture of the most important and current Major Crown Projects as well as those future projects that DND is actively staffing. While this does not provide an exhaustive list of all defence equipment projects that might be of interest to some readers, it provides broad coverage of most projects of concern, without any subjective judgments on the part of the author about which projects to examine, which might otherwise bias the analysis.

Notable Procurement Progress since September 2014

- In November 2014, contracts were awarded to General Dynamics Canada for both the design and build and In-Service Support of the anchor stations for the Mercury Global project, a Wideband Global Satellite Communications System.

- As of late 2014, the submarines acquired through the Submarine Capability Life Extension entered the "operational" phase of their life cycle: HMCS Windsor, Victoria, and Chicoutimi

- The Government of Canada announced it would acquire a fifth C17 on December 19, 2014 and the aircraft was delivered March 30, 2015

- On January 23, 2015, the build contract for the Arctic Offshore Patrol Ship was awarded, and full construction started September 1, 2015

- In January 2015, the Government of Canada announced that Irving Shipbuilding would be the prime contractor for the Canadian Surface Combatant. On May 1, 2015 the "Most Competitive Procurement Strategy" for the project was announced and the selection process for the project's Combat Systems Integrator and Warship Designer was launched

- In January 2015, the Halifax Class Modernization/Frigate Life Extension project reached Initial Operating Capability and two modernized ships have deployed operationally

- On March 31, 2015, the Request for Proposals for the Fixed Wing Search and Rescue Aircraft was released

- The Medium Range Radar contract was awarded to Rheinmetall Canada on July 27, 2015

- On June 19, 2015, the first 6 Block I Cyclone Maritime Helicopters were accepted by the Government of Canada

- On July 16, 2015, the contract for the Standard Military Pattern portion of the Medium Support Vehicle System project was awarded to Mack Defense

This section is based on the National Defence and the Canadian Armed Forces, Defence Acquisition Guide 2015, June 25, 2014 and the Department of National Defence, Project Approval Directive 2015 (Ottawa: 2015). 
Notable Delays As of October 2015, on the projects to acquire:

- Joint Support Ship Project

- Canadian Surface Combatant

- Fixed Wing Search and Rescue Aircraft

- Force Mobility Enhancements

- Lightweight Towed Howitzers

- Medium to Heavy Lift Helicopter

- Tactical Armoured Patrol Vehicle

Of the 59 Active Projects in the Defence Acquisition Guide Examined:

- 3 per cent are Early

- 34 per cent are On Schedule

- 63 per cent are Late.

\section{DEFENCE PROCUREMENT UPDATE}

Past iterations of this publication have noted several problematic aspects of Canadian defence procurement that persist to this day, and delayed several of the projects discussed in detail below. This includes multiple issues related to military operational requirements, such as producing numerous Statement of Operational Requirements that were perceived to be written with particular suppliers in mind (see the discussion of Fixed Wing Search and Rescue Aircraft below); articulating requirements that industry could not produce within the assigned budget (Joint Support Ship); and misstating the degree to which military requirements could be met with already proven, "Off the Shelf," technology (Maritime Helicopter). Similarly, concerns about the accuracy of project costing (Future Fighter Capability) and accounting for changes to initial rough order of magnitude cost estimates over time (Medium Support Vehicle System) have been problematic. As well, many authors have argued that Canada's defence procurement system, which disperses ministerial responsibility amongst multiple government departments is the root of much difficulty. These authors contend that creating a single agency to procure defence equipment would improve procurement significantly. ${ }^{8}$ Others, however, contest the notion that this would improve the situation. ${ }^{9}$

To the extent that these issues were problematic at the time last year's update was written, they largely remain so today. This is because the projects listed in Annex 1, were all initiated years ago under a procurement system featuring the limitations identified above. There are other ongoing sources of delay that are not new in the past year, but worth noting. At the same time, there have been new sources of delay arising specifically since September 2014, when the last version of this report was published, which will be described below. The author attended the

8 Sloan, Something Has to Give, Alan Williams, Reinventing Canadian Defence Procurement (Kingston: Breakout Education Network, 2006), Dan Ross, “So Defence Procurement Is It Broken Again Or Is This Just Normal?” On Track. 18. 2: (2014).

9

J.C. Stone, A Separate Defence Procurement Agency. (Calgary: Canadian International Council and Canadian Defence and Foreign Affairs Institute, 2012) and Pierre Lageuex, "Fixing defence procurement," The Hill Times March 22, 2010. 
Canadian Association of Defence and Security Industries Canadian Armed Forces Outlooks in April 2015, and one of the most common laments from participants was the increase in the amount of 'process' involved with defence procurement and the resulting delay associated with dealing with these additional administrative procedures.

The longstanding aspects of the procurement process, outlined above, are still applicable today, but since 2009, however, a number of major steps have been added that have significantly increased the work required to successfully advance a defence procurement. These are discussed further below, with the intent of demonstrating the complexity that has been added to the already lengthy defence procurement process that existed in 2008 . Those mentioned here are not intended to be exhaustive, but illustrative of some of the more significant changes, and are depicted in Annex 3.

It should be noted that all of the additional processes have been added for a reason. The Treasury Board policies discussed below were adopted to improve upon financial and project management across government. The new steps introduced under the 2014 Defence Procurement Strategy are intended to address some of the longstanding problems with defence procurement in Canada, including the development of military requirements.

Unfortunately, for the purposes of a yearly progress report, it will take several years for the results of those changes, positive, negative or null to become apparent. There has thus been little time for these measures to have any noticeable impact on the future cohort of projects identified in Annex 2. Given the effort needed to institutionalize these changes, which in some respects remain a work in progress, the changes themselves have contributed to some of the projects delays experienced since September 2014. It remains to be seen whether they will have the intended impact of ensuring the delivery of the right equipment in a timely manner.

The need for these initiatives to be successful at reducing delays is apparent. One metric for assessing the degree of delays in the procurement system is DND's ability to secure Preliminary Project Approval or Effective Project Approval from the Minister of National Defence and the Treasury Board. As discussed above, these approvals are required for a project to enter into the Definition or Implementation stages of procurement. Since 2009, the number of approvals received by DND annually has fallen off dramatically. In 2014/2015 DND secured only half the number of combined approvals that it did in 2009/2010. Since the demand for these approvals has not been reduced, this has presented a significant problem.

\section{SOURCES OF DELAY SINCE SEPTEMBER 2014}

Since September 2014, there has been a significant degree of turnover in the senior leadership at National Defence. In January 2015, the Deputy Minister was replaced, as was DND's Assistant Deputy Minister Finance/Chief Financial Officer, and the Assistant Deputy Minister 
Materiel (the head of the Materiel Group, DND's procurement organization). ${ }^{10}$ The next month, Jason Kenny replaced Rob Nicholson as the Minister of National Defence. ${ }^{11}$ In June, a new Chief of Force Development (the officer responsible for integrating the military's capability development activities) was appointed, and then in July, General Jonathan Vance replaced General Tom Lawson as the Chief of Defence Staff.

In effect, the three senior leaders in the DND and the CAF along with multiple others critical to the defence procurement process were replaced in the first seven months of 2015. As well, a transition in the Assistant Deputy Minister for Acquisitions at Public Works and Government Services Canada and with the chair of the Defence Procurement Strategy Secretariat occurred. This huge degree of turnover in a short time period delayed progress on a number of files. The incoming leadership cohort had to be briefed on their entire slate of responsibilities, including individual capital equipment procurements, DND's financial plans, of which capital equipment purchases form a significant component, and the list of priority projects discussed below.

The federal election campaign that started on August 2 left DND, along with other federal departments, unable to secure any further Minister of National Defence or Treasury Board approvals until the next federal Cabinet is appointed. Thus, the 2015 Canadian federal election played a role in limiting progress on some files. Paradoxically, it should also be noted that much of the procurement progress since September 2014, was announced immediately prior to the start of the election.

\section{ONGOING SOURCES OF DELAY}

\section{An Increased Workload and a Lack of Capacity}

One significant contributor to the current difficulty facing defence procurement is the mismatch between the procurement workload and the capacity of the defence procurement system. ${ }^{12}$ Beginning in 1989, DND entered into a decade of cascading budget cuts as the federal government attempted to eliminate the deficit. Although defence spending began to rise in 1999, it did so gradually and with little money allocated for defence procurement. This changed in 2005 when the Martin government pledged a \$12 billion increase to the defence budget over five years followed closely by another $\$ 5$ billion in funding a year later from the Harper government. A significant share of this combined budget increase was allocated to defence procurement. As a result, in the span of a few short years DND received a massive infusion of

10 Lauara Payton, "Richard Fadden named national security adviser to Stephen Harper," CBCNews.ca, January 06, 2015 http:// www.cbc.ca/news/politics/richard-fadden-named-national-security-adviser-to-stephen-harper-1.2891626, National Defence and the Canadian Armed Forces, "Mr. Claude Rochette - Biography,” May 14, 2015 http://www.forces.gc.ca/en/about-org-structure/ assistant-deputy-minister-finance-corp-services-bio.page, Prime Minister of Canada, Stephen Harper, "Prime Minister Stephen Harper Announces Changes to the Senior Ranks of the Public Service," January 26, 2015 http://pm.gc.ca/eng/news/2015/01/26/pm-announces-changes-senior-ranks-public-service

11 Mark Kennedy, "Stephen Harper looks for political safety in cabinet shuffle.” Ottawa Citizen, February 9, 2015 http:// ottawacitizen.com/news/politics/jason-kenny-becomes-new-defence-minister-nicholson-moves-to-foreign-affairs

12 This section draws on work previously published in David Perry, Putting the 'Armed' back into the Canadian Armed Forces (Ottawa: CDA Institute, 2015). See also Philippe Lagassé, Recapitalizing the Canadian Forces Major Fleets (Calgary: CIC \& CDFAI, 2012) 
procurement funds. ${ }^{13}$ Between 2004 and 2009, for instance, DND's procurement budget nearly doubled, increasing by 90 per cent after inflation..$^{14}$

This increase in funding was not matched by the capacity to manage it. During the 1995 Program Review, DND, Industry Canada, Public Works and Government Services Canada were amongst the small group of departments most heavily affected by public services downsizings. As a result, large numbers of procurement officials, including many of the most experienced, left the public service as Canada "significantly reduced its own capacity to manage...projects." 15 Auditor General reports in both 1998 and 2004, subsequently noted inexperience, inadequate training and insufficient staff as problems with defence procurements. $^{16}$

The impact on the Materiel Group is the easiest to observe by comparing the size of its workforce against the DND's spending on capital equipment procurement. In 1989, the Materiel Group employed approximately 9,000 people performing roles comparable to the ones the organization performs today and that year spent roughly $\$ 3$ billion on capital procurement, meaning there were roughly 3,000 staff working to spend each billion dollars' worth of procurement funds. As a result of Program Review, by 2003 the Material Group had shrunk to 4,200 positions and that year spent roughly $\$ 1.6$ billion on procurement, for a ratio of approximately 2,600 staff per one billion in procurement funds. By 2009, staffing in the Materiel Group had increased to 4,355, and DND spent $\$ 2.4$ billion, for a ratio of 1,800 staff per billion dollars of capital projects. Over two decades, DND's procurement workload, relative to staff, has almost doubled. After 2010, this situation worsened, because the Materiel Group was reduced by 400 positions as part of DND's deficit reduction measures. This was not matched by a commensurate reduction in the organization's workload. ${ }^{17}$

How this state of affairs arose given the significant procurement demands placed on DND since 2005 is unclear as is the extent of the mitigation measures required to address it, although both of these issues warrant further detailed study. There has, however, been a recognition that it is a problem. The most recent Departmental Performance Report from National Defence continues to cite "capacity"18 as one of the reasons for schedule delays, as have previous versions of the same document. Similarly, shortages of project staff in the Canadian Army, RCN and RCAF were cited as reasons for the delays in some of the projects listed in the 2015 Defence Acquisition Guide. ${ }^{19}$ The Materiel Group is currently attempting to hire more staff, but to date these efforts have not produced tangible results. The outcome of the 2015 federal election will

\footnotetext{
13 David Perry, “A Return to Realism,” Defence Studies, 14, no. 3 (2013): 338-360

14 This data comes from the Receiver General of Canada, The Public Accounts of Canada, Vol. II. (Ottawa: Various years) These were converted to \$1993/1994 using the Defence Economic Model by the author.

15 CADSI Marine Industries Working Group. Sovereignty, Security and Prosperity. Ottawa: CADSI, May 2009. 34.

16 Canada, Office of the Auditor General of Canada. Chapter 3: National Defence - Equipping and Modernizing the Canadian Forces. Ottawa: 1998. Canada, Office of the Auditor General of Canada. Chapter 3: National Defence - Upgrading the CF-18 Fighter Aircraft. Ottawa: 2004

17 This data comes from the Receiver General of Canada, The Public Accounts of Canada, Vol. II. converted to \$1993/1994 using the Defence Economic Model by the author. See Perry, Putting the 'Armed' Back Into the Canadian Armed Forces

18 DPR 2013/2014, p 40.

19 Confidential interviews, Ottawa 2015.
} 
hopefully improve upon this situation, as the Liberal Party of Canada pledged to "increase the capacity of National Defence's acquisition branch" ${ }^{20}$ during their campaign.

\section{POINTS OF CONCERN}

\section{Increased Process}

\section{Treasury Board Policies}

The impact of this increased workload and lack of capacity has been exacerbated by significant changes to the process for procuring defence equipment. In 2007 the Treasury Board introduced a new Policy on Investment Planning that took effect in 2009 beginning with an initial tranche of departments including DND. ${ }^{21}$ The intent of the policy is to achieve value for money and sound stewardship by ensuring "a diligent and rational manner of resource allocation for both existing and new assets." 22 These plans must be submitted to the Treasury Board Secretariat every three years, and reflect all departmental investment decisions, including procurement of defence equipment.

As projects move through the stages of the procurement process, an Investment Plan Change Management process is used to manage the impact of changes to individual project's costs on the overall investment plan. This requires an Investment Plan Change Proposal and an Investment Plan Change Impact Analysis. The latter document requires approval from DND's Program Management Board and financial attestation from DND's Chief Financial Officer. Since July 2013, if the project value exceeds \$50 million, approval from the recently created Investment Resource Management Committee, chaired by the Deputy Minister is also required to make any changes. This time and labour intensive process of assessing and attesting to the impact of changes is needed for both Preliminary Project Approval and Effective Project Approval. ${ }^{23}$

DND's first investment plan expired in 2012 and the department had difficulty securing approval for a follow-on document, which did not occur until June of 2014. During the 15 months between the time DND's first plan expired and the new one was approved, DND's investment plan was 'frozen.' This was significant, as inclusion in the Investment Plan is required before projects can go forward for Preliminary Project Approval. This meant DND was held to the funding level in the initial document and could not introduce any projects with additional costs without removing projects of equal cost as an offset. As a result, in a few instances, previously planned projects were removed to accommodate the inclusion of new

20 Liberal Party of Canada, A New Plan to Strengthen the Economy and Create Jobs with Navy Investment (Ottawa: 2015), 3.

21 Treasury Board of Canada Secretariat. "Policy on Investment Planning - Assets and Acquired Services." Last modified November 12, 2013 http://www.tbs-sct.gc.ca/pol/doc-eng.aspx?id=18225

22 Treasury Board of Canada Secretariat. "Policy on Investment Planning - Assets and Acquired Services." Last modified November 12, 2013 http://www.tbs-sct.gc.ca/pol/doc-eng.aspx?id=18225

23 Department of National Defence, Project Approval Directive 2015 (Ottawa: 2015). National Defence and the Canadian Armed Forces, "Former DM Reflects on "One of the Best Jobs in Town," February 13, 2015 http://www.forces.gc.ca/en/news/article. page?doc $=$ former-dm-reflects-on-one-of-the-best-jobs-in-town/i6jaw8wr 
ones. More significantly, DND built up a substantial backlog of projects that it would have otherwise moved into the Definition stage, but did not because the investment plan was frozen. The impacts of this backlog are still being felt as DND attempts to catch up for lost time.

In 2007, the Treasury Board of Canada also introduced a new Policy on the Management of Projects which took effect December 2009. ${ }^{24}$ The objectives of this policy are to ensure that the "appropriate systems, processes and controls for managing projects are in place" and also to "support the achievement of project and program outcomes while limiting the risk to stakeholders and taxpayers." ${ }^{25}$ This process significantly changed the process for securing Preliminary Project Approval and Effective Project Approval, moving away from the past model that used project costs to determine if the Minister of National Defence or Treasury Board could grant the approvals. The new policy is based on a department's capacity to manage projects overall and the level of risk and capacity required to successfully manage each one of them.

Under the Policy on Investment Planning, departments are responsible for conducting their own Organizational Project Management Capacity Assessment when submitting their investment plans. This assessment evaluates the department's ability to manage projects, is rated on a four point scale and examines a number of criteria across three areas: Organizational integration; core project management; and supporting project management. ${ }^{26}$ DND is then responsible for creating a Project Complexity and Risk Assessment for each one of its projects that rates their "project characteristics; strategic management; procurement; human resources; business; and project management integration." 27 This assessment is then presented to the Treasury Board Secretariat, which determines whether the Minister of National Defence or Treasury Board will provide approval for the project. All projects with a Project Complexity and Risk Assessment that exceeds the Department's Organizational Project Management Capacity Assessment rating are automatically subject to Treasury Board review. ${ }^{28}$

Under the initial 2009 investment plan, DND's Organizational Project Management Capacity Assessment rating was three. For its investment plan approved in 2014, however, this rating was reduced to two. This means that projects with a rating of three which could previously go through a less time intensive Minister of National Defence approval process, must now go to the Treasury Board for Preliminary Project Approval and Effective Project Approval.

A project's Project Complexity and Risk Assessment rating must be revised prior to moving into the Definition and Implementation stages. Furthermore, the department must submit a

24 Treasury Board of Canada Secretariat. "Policy on the Management of Projects." Last modified November 12, 2013 http://www.tbs-sct.gc.ca/pol/doc-eng.aspx?id=18229\&section=text\#sec5.1.

25 Ibid.

26 Treasury Board of Canada Secretariat.” Organizational Project Management Capacity Assessment Tool.” Last modified May 1, 2013 http://www.tbs-sct.gc.ca/pm-gp/doc/ompca-ecogp/ompca-ecogp-eng.asp.

27 Treasury Board of Canada Secretariat. "Project Complexity and Risk Assessment Tool.” Last modified May 1, 2013 http://www.tbs-sct.gc.ca/pm-gp/doc/pcra-ecrp/pcra-ecrp-eng.asp

28 The Treasury Board Secretariat can also decide that even projects with a Project Complexity and Risk Assessment that would allow the Minister of National Defence to provide an approval must be approved by the Treasury Board. Department of National Defence, Project Approval Directive. (Ottawa: 2015), 115. 
Project Approval Brief to the Treasury Board Secretariat if the Project Complexity and Risk Assessment requires that Treasury Board grant the approval. This document provides: A synopsis of the core project documents; describes the expected business outcomes and the significance of the project to achieving program and government objectives; outlines potential options and the performance indicators to be measured; provides an evaluation strategy that identifies critical project milestones, ensuring objectives are met and that value for money is achieved. ${ }^{29}$

In combination, the Treasury Board Policies on Investment Planning and Management of Projects have increased the rigour with which Canada makes investments and manages projects. At the same time, they have added considerably to the complexity of the defence procurement process.

\section{The Independent Review Panel for Defence Acquisition}

In addition to the changes resulting from these new Treasury Board policies, others have arisen with the introduction of the Defence Procurement Strategy which is intended to deliver the right equipment in a timely manner, leverage those purchases to create jobs and economic growth, as well as streamline the defence procurement processes. ${ }^{30}$ As part of this strategy, an Independent Review Panel for Defence Acquisition was created to provide "an independent, third-party challenge function related to the requirements for major procurements." ${ }^{31}$ The panels' mandate is therefore to help improve the generation and credibility of military requirements by providing advice to the Minister of National Defence and the Deputy Minister. As such, it is intended to address several problematic aspects of defence procurement discussed earlier that have been attributed to the way military requirements have been generated in the past. Announced in February 2014, the panel began operating in July 2015.

This challenge function is designed to occur at two points in the procurement process. The first occurs at the start of the Options Analysis stage. This first review examines a project's Strategic Context Document, including the initial description of military requirements and the options identified for further examination. A second review of the project's Business Case Analysis occurs later in Options Analysis, which examines the results of the options analysis, selection of the preferred option, and the preliminary Statement of Operational Requirement. Between the two reviews, the panel can also engage as necessary to ensure that issues raised during the first review are addressed and resolved.

The experience suggests that it will take some time for the procurement system in National Defence to adapt to the review process. There appears to be some uncertainty amongst procurement officials regarding what type of documentation the panel needs to conduct its reviews, the exact scope of its mandate, and concern about the time and work involved in the

29 Department of National Defence, Project Approval Directive 2015

30 Public Works and Government Services Canada. "Defence Procurement Strategy." Last modified September 8, 2014, http://www.tpsgc-pwgsc.gc.ca/app-acq/stamgp-lamsmp/sskt-eng.html.

31 National Defence and the Canadian Armed Forces, "Terms of Reference for the Independent Review Panel for Defence Acquisition,” June 1, 2015 http://www.forces.gc.ca/en/business-how-to-do/irpda-terms-of-reference.page 
process. $^{32}$ The panel's mandate as originally announced indicated that it was to validate military requirements. ${ }^{33}$ The panel's actual Terms of Reference, however, make clear that doing so requires assessing numerous other factors including: The projects' alignment with government policy; fit with the capabilities of key allies; rationale for the options examined; the complexity of the proposed requirements; alignment between various requirements documents; potential suppliers; possible role for Canadian industry; schedule risks; anticipated support concept; cost drivers; and the assumptions used to estimate costs. ${ }^{34}$ Thus, to appropriately review operational requirements the panel has been directed to consider a multitude of other factors.

A process of adjustment will necessarily need to occur as procurement staff gain a better understanding of how the panel provides its challenge function. The desired outcome is that the requirements for the projects presented to the Minister of National Defence or Treasury Board for approval are clearly and appropriately stated, which would presumably facilitate those approvals. Ensuring that these approvals are granted expeditiously is crucial to improving the overall functioning of the procurement system. This process has added some additional time to the Options Analysis stage for some of the first projects to come before it, although the intent is that this would save time later on in the Definition stage. Because of the restrictions imposed by the federal election and subsequent transition in government, as of this writing, none of these projects have gone forward for Preliminary Project Approval, making it impossible to assess the impact of the new challenge function on overall procurement timelines.

\section{Defence Procurement Strategy Governance}

Outside of DND, other changes have been introduced to implement the Defence Procurement Strategy. The most notable of these is the creation of an enhanced interdepartmental governance arrangement, all of which is led by Public Works and Government Services. This has seen the creation of a permanent Working Group of Ministers, chaired by the Minister of Public Works and Government Services, and including the ministers of National Defence, Industry, and International Trade. The Working Group was created "to ensure shared accountability in defence procurements to enable these to proceed faster and in a more efficient and coordinated manner." 35 It serves as a forum for advice, discussion, and issues resolution for major procurement projects. The Working Group is supported by a permanent Deputy Ministers Governance Committee that provides guidance for defence procurements and aims to ensure timely and appropriate decisions among competing objectives associated with particular procurements. ${ }^{36}$ Beneath that organization, subsequent committees of Assistant Deputy Ministers, Director's General and Directors operate for projects of progressively lower cost.

32 Confidential Interviews (Ottawa: 2015).

33 National Defence and the Canadian Armed Forces, "Defence Procurement Strategy and the New DND Challenge Function," February 5, 2015 http://www.forces.gc.ca/en/news/article.page?doc=defence-procurement-strategy-and-the-new-dnd-challengefunction/hr7jbfih

34 Ibid.

35 Public Works and Government Services Canada, “Defence Procurement Strategy,” November 19, 2014. http://www.tpsgc-pwgsc.gc.ca/app-acq/stamgp-lamsmp/streamlined-eng.html

36 Ibid. 
These committees are supported by a permanent Defence Procurement Strategy Secretariat that undertakes and supports numerous roles including: Ensuring early engagement occurs with industry; developing and integrating industrial offset arrangements; developing options to support decision-making; using independent advice to strengthen the integrity of the procurement process; and using an issue resolution approach to address problems quickly and effectively. Finally, the Secretariat is also responsible for assessing and evaluating the performance of the Defence Procurement Strategy. ${ }^{37}$ These committees are generally involved in at least three points in the procurement process, early in Options Analysis, late in Options Analysis and prior to the release of a Request for Proposals.

The Defence Procurement Strategy Secretariat is still being institutionalized but has now taken over the functions of the secretariats that used to exist for the Fixed Wing Search and Rescue Aircraft and the New Fighter Capability. The National Shipbuilding Procurement Strategy Secretariat, however, continues to manage the Crown's relationships with the shipyards, while supporting the Defence Procurement Strategy Secretariat on intergovernmental issues. At present, DND is still updating its internal procurement guidelines to reflect the new processes associated with these intergovernmental arrangements. ${ }^{38}$

More broadly, the Defence Procurement Strategy Secretariat efforts to streamline the defence procurement process are now underway. These are intended to reduce procurement timelines in all relevant components of the procurement bureaucracy, concentrating on the period between the start of Definition to the point a project reaches IOC in Implementation. This effort is crucial to reducing the procurement delays detailed below, but is nascent.

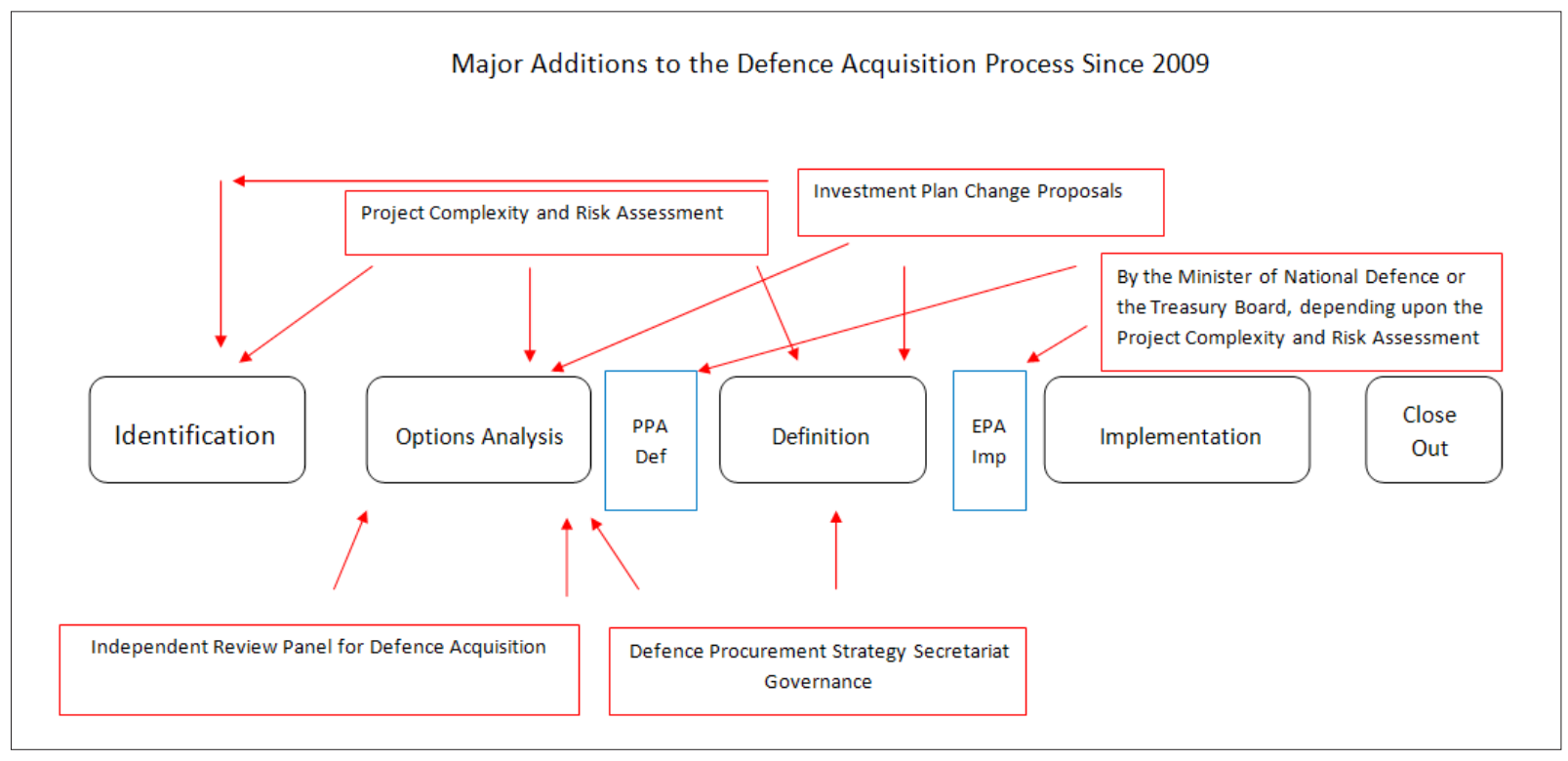

37 Ibid.

38 Confidential Interviews, 2015. 


\section{POSSIBLE IMPROVEMENTS SINCE 2014}

\section{Costing}

While a number of changes to the process for making defence procurements have added potential sources of delay, at the same time some potentially beneficial changes have been enacted since September 2014. Improvements continue to be made to the way DND conducts costing of its projects as well as how the Treasury Board Secretariat evaluates these costs. In its most recent planning documents, DND has committed to investments in individual occupational training that will include the development of costing expertise, improvements to the DND costing handbook, and improved costing in support of DND's investment planning process. ${ }^{39}$ This would all help improve DND's ability to develop cost estimates appropriate for the recently adopted Treasury Board Life Cycle Cost framework. This has also required an expansion in the size of DND's Assistant Deputy Minister Finance and Corporate Services organization, responsible for such matters, to accommodate these additional demands. Similarly, in 2014, the Treasury Board Secretariat began establishing a Costing Centre of Expertise "to improve both the capacity to challenge costs and the quality of financial information provided for decision making." 40

\section{Prioritization}

Further, the impact of these improvements to DND's costings is likely to be more significant than they would have been in the past given recent decisions to concentrate these scarce resources more strategically. Following the approval of its investment plan in 2014, DND moved away from a project by project procurement approach, to one focused on a portfolio of priority projects upon which it intends to concentrate resources. This was intended to help rationalize the competing project demands against the available funding room in the investment plan, in a way that provides the overall maximum benefit. This was initiated with the Capital Investment Program Plan Review process, a "comprehensive analysis process for assessing projects proposed for inclusion in the Investment Plan."41 This used a project's costs and a prioritized ranking of its importance based on government policy and priority, amongst other factors, to maximize the use of available fiscal room in the investment plan. ${ }^{42}$ This process produced a list of key projects that could be brought into the investment plan which formed the basis for a final list of projects to move forward as an Options Analysis portfolio. At the same time, a second list of priority projects for which funding could not be immediately identified was also compiled. Whereas the historical project by project approach precluded much consideration of the holistic impact of decisions on individual projects, this analysis allowed a much greater discussion about the opportunity costs of advancing on some

39 Department of National Defence and the Canadian Armed Forces, Report on Plans and Priorities 2015-16.

40

Treasury Board Secretariat, Report on Plans and Priorities 2014/2015 (Ottawa: 2014)

https://www.tbs-sct.gc.ca/rpp/2014-2015/tbd/tbd01-eng.asp

41 Department of National Defence and the Canadian Armed Forces, Departmental Performance Report 2013/2014 (Ottawa: 2014), 42.

42 M. Rempel and C. Young, The Portfolio Creation Model developed for the Capital Investment Program Plan Review (CIPPR) Ottawa: DRDC, November 2014. http://cradpdf.drdc-rddc.gc.ca/PDFS/unc194/p800552_A1b.pdf 
projects, and not others. The intent is to have the entire Options Analysis project portfolio approved by the Investment Resource Management Committee for inclusion in the investment plan as a package, and concentrate departmental resources, including costing capability, on this portfolio. The approval of this portfolio was delayed by the senior leadership turnover described above, and then the federal election.

\section{Streamlining}

Another initiative that has been under development since 2013, and recently approved, is the Project Approval Process Renewal. This is intended to reduce the time involved in DND's internal processes for approving projects (while maintaining Treasury Board policy compliance) thereby increasing project throughput. ${ }^{43}$ The need to improve these processes stems from the recognition that a "complex departmental/Treasury Board Secretariat corporate submission process [the process required to secure either Preliminary Project Approval or Effective Project Approval]" 44 is one of the factors contributing to schedule delay. The intent is to allow the relevant departmental committees and senior officials to select from the Options Analysis portfolio and projects already in the Definition or Implementation stages a second list of projects upon which departmental efforts to secure approvals will focus.

These efforts have been focused on the subset of DND's overall projects that the Minister of National Defence has authority to approve. These less complex files represent a majority of DND's projects by number, but a minority of projects by dollar value. The objective is to change the internal approval process at National Defence so that projects can move through the system without time consuming formal re-approvals at the Ministerial or senior official level, so long as the changes to projects as they move through their life cycle remain within reasonable bounds.

This would replace an existing system that requires time and staff intensive formal re-approvals at the Ministerial or senior official level for even relatively minor changes to project's costs or schedule, because the existing one-size fits all approval system is applied uniformly to both low risk and highly complex projects. If successful, it will allow for a reprioritization of limited staff capacity to the complex projects which require Treasury Board approvals. If the efforts to improve the process for securing approvals from the Minister of National Defence are successful, they could then be extended to the projects that must go to the Treasury Board as well. Given the dramatic reduction in DND's ability to obtain approvals since 2009, making progress on this file is crucial.

\footnotetext{
43 Department of National Defence and the Canadian Armed Forces, Defence Renewal Plan. (Ottawa: 2013$), 71$.

44 DPR 2013/2014, p 40.
} 


\section{ANNEX 1: STATUS REPORT ON MAJOR CROWN PROJECTS}

This section is drawn on information published in DND's Status Reports on Major Crown Projects. As for presentation style, the first page for each project itemizes the Project Budget for the acquisition component of the procurement where this information was obtainable, ${ }^{45}$ and includes a Project Description and Explanation of Variance, which articulates why deviations from the original schedule have occurred. The second page records the project's progress according to the major procurement milestones published in the document. In the "Initial" column, the first publically available data on the project is included. Of note, due to the age of some projects there were data problems obtaining consistent records for the older projects in this Annex. Only the Status Reports on Major Crown Projects published since 2006/2007 are available on the DND website. The author used any data provided in DND's Report on Plans and Priorities from previous years to supplement this information where possible, but this still presented an inconsistent set of data entries for the "Initial" column for older projects.

The "2014" column shows updated data from the Report on Plans and Priorities 2014/2015, while the "Most Recent" column shows the most recently available information, generally the Report on Plans and Priorities 2015/2016. These three columns are intended to demonstrate progress since the project was initially included for publication, and then specifically progress over the last year. A dotted line through the middle of this page indicates that the program was significantly changed after its initial inclusion, either through cancellation or a project 'reset' and thus the data below the line is applicable to the revised project schedule only.

Where a checkmark symbol $(\checkmark)$ is entered, this indicates that the milestone was achieved on the schedule previously indicated. Finally, this section concludes with a section specifically indicating Significant Progress since September 2014, the date the last iteration of this report was published. The data used in this Annex is primarily drawn from open sources, particularly the Report on Plans and Priorities and Departmental Performance Reports for DND. Where available, this was supplemented by other public sources such as Auditor General of Canada or DND's Chief Review Services (the internal DND auditor) reports.

It should be recognized that there is an information asymmetry between the projects that have deviated the least and the most from their original schedules. Generally only the most complex projects with the highest level of risk, and thus the ones most likely to be delayed, become the subjects of these audits. There is thus generally more information to explain delay than there is to explain why a project remained on schedule.

Similarly, there was significant variation in terms of which milestones the projects reported, and when they first reported them. As an example, the Arctic Offshore Patrol Ship published an IOC target the first time the project was mentioned in the Status Report on Major Crown Projects. The Submarine Capability Life Extension, however, did not publish an IOC date until nine years after the project was first detailed in the Reports on Plans and Priorities in 1999, the

45 Data of Project Budgets was obtained from public announcements as well as the Department of National Defence Department Performance Report 2013/2014 (Ottawa: 2014) "Status Report on Projects Operating with Specific Treasury Board Approval," November 5, 2014 http://www.forces.gc.ca/en/about-reports-pubs-departmental-performance/2014-status-report-tb-approvaltable.page 
same year the contract for the vessels was signed. This type of information disparity therefore precluded meaningful systematic comparisons and analysis across these projects.

As well, it should also be noted that not all schedule milestones are equally important, with Project Close Out, for instance, less important than the others. Once a project hits FOC, the most significant work, requiring the most staff effort, has been completed. Often after this stage, the remaining tasks will be transferred over to the Equipment Program Managers in the Materiel Group. Often, closing out a project can take significant time after FOC is achieved due to the need to receive all invoices, and finalize infrastructure, force generation, and supply chain arrangements. The Canadian Search and Rescue Helicopter project, for instance, reached FOC in 2004, but has not yet been closed out. Two other projects in this list, the Submarine Capability Life Extension and Tank Replacement Project have similarly reached FOC, but are included in this list because the projects have not yet been fully completed.

In their totality, these individual project descriptions do reveal that every single one of the projects examined have experienced a delay in achieving at least one milestone. None of the projects that had a single FOC date achieved that milestone on schedule, although the Halifax Class Modernization/Frigate Life Extension, Light Armoured Vehicle III Upgrade (LAV III UP), and Protected Military Satellite Capability projects remain on track to do so, and the Mercury Global project is slated to achieve this milestone a year early.

Only the Submarine Capability Life Extension achieved IOC on schedule (and this schedule was set nine years after the vessels were acquired), while the Halifax Class Modernization/ Frigate Life Extension did so only one month behind schedule, and the Airlift Capability Project - Strategic, achieved this marker six months late. Multiple other projects that have yet to reach IOC are delayed by multiple years in doing, with the Joint Support Ship slated to achieve this milestone eight years later than originally intended. 
Annex 1 Projects Listed in the 2015/2016 RPP:

1. Airlift Capability Project - Strategic

2. Airlift Capability Project - Tactical

3. Arctic Offshore Patrol Ship

4. Canadian Cryptographic Modernization Program

5. Canadian Search and Rescue Helicopter Project

6. Canadian Surface Combatant Project $\checkmark$

7. Future Fighter Capability $\checkmark$

8. Fixed Wing Search and Rescue Aircraft Replacement $\checkmark$

9. Force Mobility Enhancement

10. Halifax Class Modernization/Frigate Life Extension

11. Intelligence, Surveillance, Target Acquisition and Reconnaissance

12. Joint Support Ship $\checkmark$

13. Joint Unmanned Surveillance and Target Acquisition System $\checkmark$

14. Light Armoured Vehicle III Upgrade Project

15. Lightweight Towed Howitzer

16. Maritime Helicopter Project $\checkmark$

17. Medium Support Vehicle System Project $\checkmark$

18. Medium-to-Heavy Lift Helicopter $\checkmark$

19. Mercury Global

20. Protected Military Satellite Communications $\checkmark$

21. Submarine Capability Life Extension

22. Tactical Armoured Patrol Vehicle

23. Tank Replacement Project 


\section{Airlift Capability Project - Strategic}

Project Budget: $\$ 1.8$ billion

\section{Project Description:}

This project originated as a Conservative Party of Canada campaign promise in the 2006 election to acquire "a fleet of at least three strategic lift aircraft." ${ }^{\prime 6}$ That scope was subsequently expanded to acquiring four aircraft. All aircraft were delivered by 2008 and this initial project was closed out after it hit FOC in 2012. The Government of Canada announced it would acquire a $5^{\text {th }} \mathrm{C}-17$ on December 19, 2014 using the remaining funding from the acquisition budget of the original aircraft purchase which was completed roughly $\$ 415$ million under budget. $^{47}$

\section{Explanation of Variance:}

Delivery of the first four aircraft occurred very quickly, as Canada used the Advance Contract Award Notice (ACAN) process, a procedure used to advertise an intent to sole source a purchase, to procure the $\mathrm{C}-17$ specifically. Canada also bought a virtually unmodified aircraft off an existing American production line, with the concurrence of the United States Government, at a time when Canada had a need for airlift because of operations in Afghanistan. The project was also a personal priority of the new Minister of National Defence, Gordon O'Connor, and benefitted from the strong working relationship between Chief of Defence Staff General Rick Hillier and Deputy Minister Ward Elcock. ${ }^{48}$ The InService Support (the activities required to sustain the operation of a military fleet over its lifetime) arrangements secured for the fleet tapped into the existing world-wide arrangements established for American C-17 fleet, facilitating a rapid acquisition.

Despite the speed of implementation, FOC of the original four aircraft was delayed due to complexities associated with transitioning to the In-Service Support arrangements, which required the full availability of infrastructure at Canadian Forces Base Trenton. ${ }^{49}$

The extremely rapid acquisition of the $5^{\text {th }}$ aircraft is attributable to similar dynamics. Boeing had built 10 additional C-17s, "white tailed"50 in that they had no identified customer in mind. Canada therefore purchased an existing aircraft, already produced, without any modifications.

\footnotetext{
46 Conservative Party of Canada, “Conservatives call for boost to Canadian Forces,” December 19, 2005.

47 Canada, Department of National Defence and the Canadian Armed Forces, "Increased Air Power for the Royal Canadian Air Force - Fifth CC-177 Globemaster to Increase RCAF Airlift Capability,” December 19, 2014 http://news.gc.ca/web/article-en.do?nid=916009, DPR 2013/2014

48 Rick Hillier, A Soldier First Toronto: Harper Collins, 2008.

49 RPP 2010-2011

50 Nigel Pittaway “Boeing: Five C-17As Still for Sale,” Defence News, April 23, 2015 http://www.defensenews.com/story/defense/ air-space/support/2015/04/23/australia-c17-boeing-air-force-globemaster/26137493/
} 


$\begin{array}{llll}\text { Major Milestones: } & \text { Initial }^{51} & \mathbf{2 0 1 4}^{52} & \text { Most Recent }^{53} \\ \text { Memorandum to Cabinet } & \text { June 2006 } & \checkmark & \\ \text { Effective Project Approval } & \text { June 2006 } & \checkmark & \\ \text { ACAN Notice } & \text { July 2006 } & \checkmark \\ \text { Contract Award } & \text { Feb, 2007 } & \checkmark \\ \text { First Delivery } & \text { Aug 2007 } & \checkmark & \\ \text { Last Delivery } & \text { Apr 2008 } & \checkmark^{54} & \\ \text { IOC } & \text { Spr 2008 } & \text { Oct 2008 } & \checkmark \\ \text { FOC } & \text { Sum 2009 } & \text { Dec 2012 } & \checkmark\end{array}$

-The Initial Project Closed After Reaching FOC for the First 4 Aircraft

Amended Project Approval for $5^{\text {th }}$ Aircraft

Dec $2014 \checkmark$

IOC $5^{\text {th }}$ Aircraft

Apr 2015

FOC $5^{\text {th }}$ Aircraft

Aug 2015

Project Close Out

Dec 2015

\section{Notable Progress since September 2014:}

The Government of Canada announced it would acquire a $5^{\text {th }} \mathrm{C}-17$ on December 19, 2014. It was delivered to Canadian Forces Base Trenton on March 30, 2015.55

51 The footnotes in each header category indicate that the information contained in the column is from that source unless otherwise specified. In the interest of brevity, many of the citations employ an abbreviation. RPP indicates that the reference is from the Department of National Defence Report on Plans and Priorities for the indicated Fiscal Year. DPR indicates that the reference is from the Department of National Defence Departmental Performance Report from the indicated Fiscal Year. Information in this column is from Department of National Defence Departmental Performance Report 2006/2007, (Ottawa: 2006) or DPR 2006/2007.

52 RPP 2014/2015

53 RPP 2015/2016

54 David Pugliese, "Fourth C-17 Delivered to Canadian Air Force," Ottawa Citizen, April 4, 2008. http://ottawacitizen.com/news/ national/defence-watch/fourth-c-17-delivered-to-canadian-air-force

55 David Pugliese, "New RCAF Globemaster lands in Canada," Ottawa Citizen, March 312015 http://ottawacitizen.com/news/ national/defence-watch/new-rcaf-globemaster-lands-in-canada 


\section{Airlift Capability Project - Tactical}

Project Budget: $\$ 3.2$ billion

\section{Project Description:}

This project replaced the oldest members of the RCAF's fleet of C-130 Hercules aircraft. A commitment to do so first appeared in the 2005 Budget, and it was reiterated in the 2005 Defence Policy Statement. It was first brought forward for Cabinet approval in the fall of 2005 as a sole source procurement for the C-130J, but this strategy was rejected. ${ }^{56}$

This project was named as part of the Conservative Party of Canada's 2006 election platform, which committed to the "replacement of Canada's tactical airlift fleet of C-130 Hercules aircraft" 57 The project entered the Implementation stage with the December 2007 contract award to Lockheed Martin Corporation for 17 C-130J aircraft. Aircraft deliveries began in May 2010 and were completed by May 2012. The contract was subsequently amended in December 2009 to include provisions for In-Service Support, in February 2010 for maintenance training systems, and in November 2013 for the Block 7 avionics modification required to satisfy final Project Deliverables. ${ }^{58}$

\section{Explanation of Variance:}

The project was initially delayed due to the transition in government after the 2006 election. Thereafter it had to be reconciled with their Harper Government's prioritized acquisition of a strategic airlift aircraft. Once the decision was made to proceed with the purchase, it occurred rapidly, in part because the $\mathrm{C}-130 \mathrm{~J}$ was determined to be the only qualified aircraft following the Solicitation of Interest and Qualification, a procedure by where potential bidders are invited to indicate if they are interested and capable of bidding on a procurement. There was also a clear operational need due to the advanced age of the fleet being replaced, and pressing operational demand due to operations in Afghanistan. ${ }^{59}$

Delays in achieving IOC, FOC and Project Close Out appear to be due to longer than expected timelines for establishing contracts for In-Service Support, maintainer training and upgrading infrastructure at CFB Trenton. ${ }^{60}$

\footnotetext{
56 Alan Williams, Reinventing Canadian Defence Procurement, Kingston: Breakout Education Network, $2006,30$.

57 Conservative Party of Canada, “Conservatives call for boost to Canadian Forces," December 19, 2005.

58 RPP 2015/2016

59 Hiller, A Solider First.

60 DPR 2012/2013
} 


$\begin{array}{llll}\text { Major Milestones: } & \text { Initial }^{61} & \mathbf{2 0 1 4}^{62} & \text { Most Recent }^{63} \\ \text { Memorandum to Cabinet } & \text { June 2006 } & \checkmark & \\ \text { Preliminary Project Approval } & \text { June 2006 } & \checkmark & \\ \text { Effective Project Approval } & \text { Fall 2007 } & \text { Dec 2007 } & \checkmark \\ \text { Contract Award } & \text { Fall 2007 } & \text { Dec 2007 } & \checkmark \\ \text { First Delivery } & \text { Aug 2010 } & \text { June 2010 } & \checkmark \\ \text { IOC } & \text { Sum 2011 } & \text { Sep 2013 } & \checkmark \\ \text { FOC } & \text { Sum 2013 } & \text { Fall 2016 } & \text { Sep 2016 } \\ \text { Project Close Out } & \text { Win 2014 } & \text { Win 2016/17 } & \text { Dec 2016 }\end{array}$

Notable Progress since September 2014:

No Information Publicly Available.

\footnotetext{
61 DPR2006/2007

62 RPP 2015/2016

63 RPP 2015/2016
} 


\section{Arctic Offshore Patrol Ship}

Project Budget: $\$ 3.1$ billion (original) - $\$ 3.5$ billion (revised)

\section{Project Description:}

This project evolved from the 2006 Conservative Party of Canada election platform commitment to "Station three new armed naval heavy icebreakers in the area of Iqaluit." ${ }^{64}$ Over time this requirement was adapted significantly, and now calls for "an ice-capable ship" 65 that will be able to operate year-round in one meter of first-year ice with old ice inclusions, while also being able to operate in the open ocean. The ship will be fitted with a gun system suited for constabulary roles, maintain a speed of 17 knots, operate at a range of 6,800 nautical miles, operate autonomously for up to four months, and embark utility helicopters and provide limited support to the $\mathrm{CH}-148$ Cyclone discussed below.

The project originally intended to acquire six to eight vessels, but this changed following a review of the design. The current contract for five to six ships required a project increase of roughly $\$ 300$ million.

\section{Explanation of Variance:}

The Arctic Offshore Patrol Ship project was delayed by the launch of the National Shipbuilding Procurement Strategy in June 2010. This process required first competitively selecting the winning shipyards that would build the ship (announced October 19, 2011), and then negotiating Umbrella Agreements with the shipyards that lay out the terms for the overall program (completed in February, 2012). Irving Shipyards Inc., awarded the work, subsequently undertook a roughly $\$ 300$ million shipyard upgrade which saw the construction of an entirely new shipbuilding facility.

The project has subsequently employed a "design-then-build" approach which has effectively front-loaded a number of activities into a larger than usual definition contract. This effort resulted in a more costly and longer than normal Definition stage designed to help gain a better understanding of the ship design prior to beginning construction in the Implementation stage, as well as validating the new shipyard equipment and processes. The Arctic Offshore Patrol Ship project is also being used to validate the systems and processes to be used for the entire combat work package, including the Canadian Surface Combatant discussed below. ${ }^{66}$

64 Conservative Party of Canada, “Defending Sovereignty - Strengthening Canada's Arctic Forces,” December 22, 2005.

National Defence and the Canadian Armed Forces, Defence Acquisition Guide 2015, last modified June 35, 2014 http://www.forces.gc.ca/en/business-defence-acquisition-guide-2015/index.page

66 Public Works and Government Services Canada, "National Shipbuilding Procurement Strategy (NSPS)" last modified July 14, 2015 http://www.tpsgc-pwgsc.gc.ca/app-acq/sam-mps/nouvelles-news-eng.html 


$\begin{array}{llll}\text { Major Milestones: } & \text { Initial }^{67} & \mathbf{2 0 1 4}^{68} & \text { Most } \\ \text { Memorandum to Cabinet } & \text { Jan 2008 } & \checkmark & \\ \text { Preliminary Project Approval } & \text { May 2007 } & \checkmark & \\ \text { Revised Project Approval Definition 1 } & & \text { Oct 2011 } & \checkmark \\ \text { Revised Project Approval Definition 2 } & & \text { Dec 2012 } & \checkmark \\ \text { Definition Contract } & & \text { Mar 2013 } & \checkmark \\ \text { Effective Project Approval } & \text { Jan 2010 } & 2014 & \checkmark \\ \text { Contract Award (Implementation) } & \text { Jan 2010 } & 2015 & \checkmark \\ \text { First Delivery } & \text { Aug 2013 } & 2018 & 2018 \\ \text { IOC } & \text { Mar 2014 } & 2019 & 2019 \\ \text { FOC } & \text { Sum 2013 } & 2023 & 2023 \\ \text { Project Close Out } & \text { Win 2014 } & & 2024\end{array}$

Notable Progress since September 2014:

In October 2014, Task six for the construction of a test production module was issued under the definition contract and work began June 18, 2015.72 On January 23, 2015, the build contract for Arctic Offshore Patrol Ship was awarded to Irving Shipbuilding Inc., for a minimum of five ships, and significant incentives for the contractor to deliver a sixth. ${ }^{73}$ Full construction started September 1, 2015. ${ }^{74}$

67 DPR 07/08

68 RPP 2014/15

69 RPP 2015/2016

70 DPR 2006/2007

71 DPR 2006/2007

72 Public Works and Government Services Canada, National Shipbuilding Procurement Strategy (NSPS), June 18, 2015 http://www.tpsgc-pwgsc.gc.ca/app-acq/sam-mps/snacn-nsps-eng.html

73 Government of Canada, "Harper Government Awards Shipbuilding Contract That Supports Jobs Across Canada," January 23, 2015 http://news.gc.ca/web/article-en.do?nid=924929\&_ga=1.151610809.1247111679.1424449696

74 Irving Shipbuilding Inc, "Irving Shipbuilding Begins Construction of First Arctic Offshore Patrol Ship (AOPS) for Canada," September 1, 2015 http://www.irvingshipbuilding.com/BlogPage.aspx?id=609\&blogid=315 


\section{Canadian Cryptographic Modernization Program}

Project Budget: \$246 million

\section{Project Description:}

The Canadian Cryptographic Modernization Program will modernize the Government of Canada's cryptographic equipment and infrastructure in order to safeguard classified information and maintain Canada's ability to establish secure communications both nationally and internationally. The project includes the following sub-projects: Secure Voice / Telephone Re-key Infrastructure - (SV/TRI); Classified Security Management Infrastructure (CSMI); Secure Voice / Telephone Replacement (SV/TR); Combat Identification Replacement (CIR); Link Encryption Replacement (LER); Network Encryption Replacement (NER); Secure Radio Replacement (SRR)

\section{Explanations of Variances:}

The CCMP is reported to be on budget. Schedule slippage is in part due to its interdependence with the American Cryptographic Modernization Initiative and the Key Management Infrastructure Program. Canada's collaboration with the United States allows Canada to leverage American research and development and maintain interoperability with its allies, but as a result the Canadian project's timeliness must align with the American initiative. ${ }^{75}$

RPP $2015 / 2016$ 
Major Milestones:

Preliminary Project Approval (omnibus)

Preliminary Project Approval CSMI

CSMI Phase 1 Complete

Phase 1A Complete

Phase 1B Complete

CSMI Phase 2 Complete

Phase 2 Definition

Phase 2A

Phase 2B

CSMI Phase 3 Complete

SV/TR Complete

SV/TRI Complete

LER Phase 1 Complete

LER Phase 2 Complete

NER Complete

CIR Complete

SRR Complete

Project Complete

\section{Initial $^{76}$}

Mar 2005

Nov 2006

2009

2014

Mar 2012

2011

$\begin{array}{lll}- & \text { Mar 2013 } & \checkmark \\ - & 2017 & 2017 \\ - & 2019 & 2019 \\ 2016 & 2020 & 2020 \\ \text { Sep 2007 } & \text { July 2012 } & \checkmark \\ \text { Mar 2008 } & \text { Sep 2009 } & \checkmark \\ 2010 & 2020 & 2020 \\ 2016 & - & 2020 \\ 2011 & 2018 & 2018 \\ 2016 & 2018 & 2018 \\ 2016 & - & 2020 \\ 2016 & - & \text { TBD }\end{array}$

Notable Progress since September 2014:

No Information Publicly Available.

$\begin{array}{ll}76 & \text { RPP 2007/2008 } \\ 77 & \text { RPP 2014/2015 } \\ 78 & \text { RPP 2015/2016 }\end{array}$ 


\section{Canadian Search and Rescue Helicopter Project}

Project Budget: $\$ 740$ million

\section{Project Description:}

This project emerged as one half of the New Shipborne Aircraft project that was cancelled by the Chrétien Government in 1993, and subsequently split into two separate projects for Search and Rescue Helicopters and Maritime Helicopters. It replaced the CH-113 Labradors with a fleet of 15 new CH-149 Cormorant helicopters. ${ }^{79}$

\section{Explanation of Variances:}

Initial delay was the result of the Chrétien decision to cancel the original New Shipborne Aircraft project. Further delay then resulted from an initial, unchallenged, assumption that the requirement could be procured 'Off the Shelf.' In reality, an assessment found that the final aircraft delivered has less than 30 per cent commonality with the actual 'Off the Shelf' variant. This delayed the issuance of airworthiness certification, and contributed to an initial underresourcing of the Project Management Office. ${ }^{80}$

Effective Project Closure was achieved on September 15, 2004, but work is ongoing to achieve Project Close Out. A three year Technical Publication Revision Service was required to progress towards FOC, which did not begin until 2007-2008..$^{81}$ The remaining work required to achieve FOC is related to retrofits to incorporate design specifications that are completed when major maintenance is conducted on the fleet. ${ }^{82}$

\footnotetext{
79 Aaron Plamondon, The Politics of Procurement. Vancouver: UBC Press, 2010.

80 Chief Review Services, Review of the Canadian Search and Rescue Helicopter Acquisition (Cormorant) (Ottawa: Department of National Defence, 2007).

81 DPR 2006/2007

82 RPP 2015/2016
} 


$\begin{array}{llll}\text { Major Milestones: } & \text { Initial }^{83} & \text { 2014 }^{84} & \text { Most Recent }^{85} \\ \text { Preliminary Project Approval } & \text { Nov 1995 } & \checkmark & \\ \text { Request for Proposal } & \text { Nov 1996 } & \checkmark & \\ \text { Effective Project Approval } & \text { Apr 1998 } & \checkmark & \\ \text { Contract Award } & \text { Apr 1998 } & \checkmark & \\ \text { First Delivery } & \text { June 2000 } & \text { Sep 2001 } & \checkmark \\ \text { Final Delivery } & \text { July 2002 } & \text { July 2003 } & \checkmark \\ \text { Project Completion (effective) } & \text { July 2004 } & \text { Sep 2004 } & \checkmark \\ \text { Project Close Out } & \text { Win 201488 } & 2015 & 2015\end{array}$

Notable Progress since September 2014:

No Information Publicly Available.

83 RPP 1998/1999, 88-89.

84 RPP 2014/2015

85 RPP 2015/2016

86 RPP 1999/2000, 33.

87 RPP 1998/1999, 89.

88 DPR 2006/2007 


\section{Canadian Surface Combatant Project}

Project Budget: \$26 billion

\section{Project Description:}

The Canadian Surface Combatant Project will recapitalize Canada's naval fleet, through two variants: An Area Air Defence and Task Group Command and Control variant and a General Purpose variant. This was first discussed in the 2005 Defence Policy Statement which pledged to "Begin to define the requirements for a new class of surface ship to replace the current destroyers and frigates." 89 The project formed part of the 2006 Conservative Party of Canada election platform, which committed to "initiating a longer term frigate/destroyer replacement program," $" 90$ and was included in the 2008 Canada First Defence Strategy. The Project will begin with the acquisition of a replacement for Area Air Defence and Task Group Command and Control capabilities, forming the basis for the subsequent acquisition of general-purpose warships. The project was originally set to acquire 15 vessels, but this was later revised to "up to $15 "$ " vessels. Definition work began in June 2012, and has proceeded with a number of studies to inform the development of technical specifications. At the same time, numerous industry engagements have been undertaken on a range of issues related to the procurement.

\section{Explanation of Variance:}

The project is part of the National Shipbuilding Procurement Strategy, and progress on the Canadian Surface Combatant has been dependent upon progress on the other aspects of that wider strategy, detailed above. The project experienced significant delay in selecting the final procurement strategy for the project, which was originally supposed to occur in the summer of 2013. The use of 15 industry engagement sessions since 2012 is reflective of a commitment to engaging with industry, but at the same time contributed to a delay in announcing a "Most Competitive Procurement Strategy" in May 2015. Delaying this announcement in turn delayed the initiation of the selection process for the Combat Systems Integrator and Warship Designer. As a result, there now appears to be a gap of almost two years between the completion of the Arctic Offshore Patrol Ship project and the start of Canadian Surface Combatant Project construction.

Government of Canada capacity on all aspects of shipbuilding remains a key difficulty. To mitigate this lack of capacity, Canada is relying heavily on contracted third party services, which requires significant effort to obtain. In July 2015, for instance, Public Works and Government Services Canada issued a Request for Proposals for "contract negotiation expertise, advice and related training services" ${ }^{92}$ worth up to $\$ 5$ million.

89 Department of National Defence, Defence Policy Statement. (Ottawa: 2005), 14. All subsequent references to the Defence Policy Statement refer to this document.

90 Conservative Party of Canada, "Conservatives will boost defence on West Coast to protect Canadian sovereignty,” December $27,2015$.

91 Public Works and Government Services Canada, “National Shipbuilding Procurement Secretariat,” July 14, 2015 http://www.tpsgc-pwgsc.gc.ca/app-acq/sam-mps/snacn-nsps-eng.html

92 Public Works and Government Services Canada, “3RD PARTY EXPERT NEGOTIATION ADVICE (EN578-160489/A)” July 2, 2015 https://buyandsell.gc.ca/procurement-data/tender-notice/PW-XLV-577-6772 


$\begin{array}{llll}\text { Major Milestones: } & \text { Initial }^{93} & \mathbf{2 0 1 4}^{94} & \text { Most } \\ \text { Identification Phase Approval } & \text { July 200796 } & \checkmark & \\ \text { Preliminary Project Approval } & 2011 & & \\ \text { Definition Phase 1 } & & \text { June 2012 } & \checkmark \\ \text { Definition Phase 2 } & & 2016 & 2016 \\ \text { Definition Contract } & & 2016 & 2016 \\ \text { Effective Project Approval } & & 2018 & 2020 \\ \text { Implementation Contract Award } & 2015 & 2018 & 2020 \\ \text { First Delivery } & & 2025 & 2025 \\ \text { IOC } & 2021 & 2026 & 2026 \\ \text { FOC } & 2036 & 2042 & 2042 \\ \text { Project Close Out } & 2037^{97} & 2043 & 2043\end{array}$

\section{Notable Progress since September 2014:}

In January 2015, the Government of Canada announced that Irving Shipbuilding Inc. would be the prime contractor for the project. ${ }^{98}$ On May 1, 2015 the "Most Competitive Procurement Strategy" for the Canadian Surface Combatant Project was announced and the selection process for the projects Combat Systems Integrator and Warship Designer was launched ${ }^{99}$ Over the summer of 2015 an initial cost and capability reconciliation process was initiated as part of the project's Definition stage.

\footnotetext{
RPP 2011/2012

94 RPP 2014/2015

95 RPP 2015/2016

96 DPR 2010/2011

97 RPP 13/14

98 James Cudmore, “Irving named prime contractor for Canadian surface combatant warships," CBCNews.ca January 20, 2015 http://www.cbc.ca/news/politics/irving-named-prime-contractor-for-canadian-surface-combatant-warships-1.2920071

99 Public Works and Government Services Canada, "National Shipbuilding Procurement Secretariat,"
} 


\section{Fixed Wing Search and Rescue Aircraft}

Project Budget: Original $\$ 1.3$ billion, Revised, $\$ 1.55$ billion, currently a firm budget is not established. ${ }^{100}$

\section{Project Description:}

This project will replace the fixed wing component of the RCAF's search and rescue fleet. In 2004, the Martin government provided money in its budget to accelerate the replacement of search and rescue airplanes, it was mentioned specifically in 2005 Defence Policy Statement, and was first brought forward for Cabinet approval in the fall of 2005, but not approved. ${ }^{101}$ The project also appeared in the 2006 Conservative Party campaign platform, and was specifically mentioned in the 2008 Canada First Defence Strategy.

\section{Explanation of Variance:}

An internal DND audit of the project noted initial delay following the 2004 budget related to a lack of external endorsement of the project's procurement strategy, problems with the project's life cycle costing, as well as issue with its proposal for In-Service Support. ${ }^{102}$ Alan Williams described the former problem as related to the RCAF's Statement of Operational Requirement, which he contends was written by the RCAF to favour the Alenia C27J. ${ }^{103}$

The issue lingered for several years, until the National Research Council was asked by Public Works and Government Services Canada to review the project's requirements in 2009. It reported in March 2010 that "The [Statement of Operational Requirement] as written is overconstrained." 104 A revised document was finalized in December 2010, and a Public Works and Government Services Canada led secretariat was established to provide governance for the project in February 2012. Changes to the final Request for Proposals were also created by introducing a requirement for a Canadian In-Service Support Integrator to maximize the industrial benefits accruing to Canadian industry from the project's In-Service Support arrangements. ${ }^{105}$

\footnotetext{
100 According to Public Works and Government Services Canada, "Details of the final estimates will only be known when bids have been received and the successful bid is presented to the Government." Public Works and Government Services Canada, "Fixed-Wing Search and Rescue Aircraft Replacement (FWSAR) Project: Frequently Asked Questions - Q7. What is the budget for the FWSAR project?" September 11, 2015, Accessed October 17, 2015. http://www.tpsgc-pwgsc.gc.ca/app-acq/stamgplamsmp/faq-eng.html

101 Williams, Reinventing Defence Procurement

102 Chief Review Services, “Audit of the Fixed Wing Search and Rescue Project (FWSAR),”(Ottawa: Department of National Defence, May 2009)

103 Williams, Reinventing Defence Procurement, 40.

104 National Defence and the Canadian Armed Forces, "Review of the Statement of Operational Requirement for the Fixed Wing Search and Rescue Aircraft," March 12, 2010 http://www.forces.gc.ca/en/about-reports-pubs/fixed-wing-search-rescueaircraft-2010.page

105 Public Works and Government Services Canada, "Fixed-Wing Search and Rescue Aircraft Replacement (FWSAR) Project: FWSAR Project - Independent Review of Evaluation Plans, Methods and Tools" April 2, 2015, Accessed October 17, 2015. http://www.tpsgc-pwgsc.gc.ca/app-acq/stamgp-lamsmp/svtvnpro-rscfwpro-eng.html
} 


\begin{tabular}{|c|c|c|c|}
\hline Major Milestones: & Initial & $\mathbf{2 0 1 4}^{106}$ & Most Recent ${ }^{107}$ \\
\hline DND Identification stage approval & Nov 2002 & $\checkmark$ & \\
\hline Preliminary Project Approval & Spr/Sum $2009^{108}$ & Mar 2012 & $\checkmark$ \\
\hline RFP Released & Mar $2005^{109}$ & - & Mar 2015 \\
\hline Effective Project Approval & Spr $2010^{110}$ & Win 2014/15 & 2016 \\
\hline Contract Award & Spr/Sum $2010^{111}$ & Win 2014/15 & 2016 \\
\hline First Delivery & Mar- Sep $2005^{112}$ & Win $2017 / 18$ & 2019 \\
\hline $\mathrm{IOC}$ & $2018^{113}$ & 2018 & 2020 \\
\hline FOC & $2019^{114}$ & 2020 & 2022 \\
\hline Project Close Out & Spr/Sum, $2017^{115}$ & 2020 & 2023 \\
\hline
\end{tabular}

\section{Significant Progress since September 2014:}

On March 31, 2015 the Request for Proposal for the project was released. Bids were originally to be submitted by September 28, 2015, but the bid closing date was extended to January 11, 2016 at the request of bidders. This request was the result of a highly complicated, multithousand page Request for Proposal. ${ }^{116}$

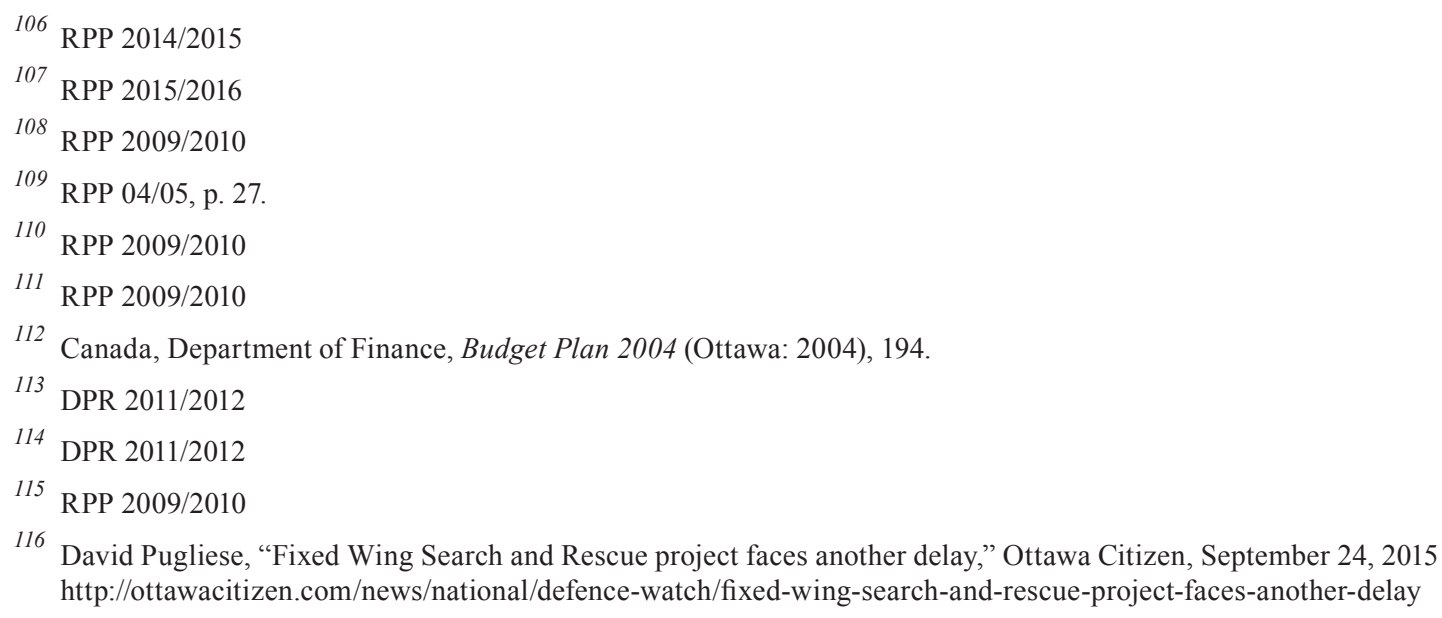




\section{Force Mobility Enhancement}

Project Budget: \$376 million

\section{Project Description:}

The Force Mobility Enhancement project is a two-phase project. In Phase 1, the project will replace Canada's aging Leopard 1 Armoured Engineer Vehicle Badger fleet with a heavily protected and mobile platform capable of supporting the newly acquired Leopard 2 Main Battle Tank until 2035. The project will then acquire 13 Leopard 2-based Armoured Engineer Vehicles, with an option of an additional five, including engineering implements for the Armoured Engineer Vehicle. In Phase 2, the project will acquire tactical mobility implements for the in-service Leopard 2 Main Battle Tank. Tactical mobility implements could include, but are not limited to, mine rollers, mine ploughs, and dozer blades. The project will also seek to acquire two Leopard 2-based Armoured Recovery Vehicles, with an option of an additional two, as support variants for the Armoured Engineer Vehicle. The Armoured Recovery Vehicles will be acquired by exercising contract options from the Tank Replacement Project.

\section{Explanations of Variances:}

On 10 December 2013, the contractor informed DND that IOC would be postponed for seven months from February 2015 to September 2015 due to delays in the design and delivery of the casted chassis modules. On August 26, 2014, DND was notified of a second delay and IOC is now expected in October 2016. This second is due to the postponement of ballistic testing by eight months. ${ }^{117}$

117 RPP 2015/2016 
Major Milestones:

Identification Phase Approval

Preliminary Project Approval

Revised Preliminary Project

Approval Phase 1

RFP Phase 1

RFP Phase 2

Effective Project Approval

Effective Project Approval Phase 1

Effective Project Approval Phase 2

Contract Award Phase 1

Contract Award Phase 2

IOC Phase 1

IOC Phase 2

FOC

Project Close Out
Initial $^{118}$

Aug 2008 121

June $2009^{122}$

Mar $2011^{123}$

Oct 2010

June 2011

Apr $2014^{126}$

Feb 2012

Nov 2011

Mar 2012

Apr 2014

Dec 2013

$2015^{127}$

$2017^{128}$
2014 $^{119}$

Sep 2008

Mar $2012^{125}$

$\checkmark$
Oct $2011^{124}$

Most Recent ${ }^{120}$

Mar 2012

Nov 2013

Apr 2012

Dec 2013

Feb 2015

Aug 2015

Dec 2016

2017
Oct 2016

Aug 2015

Dec 2017

Mar 2018

Notable Progress since September 2014:

No Information Publicly Available.

\footnotetext{
118 DPR 2010/2011

119 RPP 2014/2015

120 RPP 2015/2016

121 RPP 2010/2011

122 RPP 2010/2011

123 RPP 2010/2011

124 DPR 2010/2011

125 RPP 2012/2013

126 RPP 2010/2011

127 RPP 2010/2011

${ }^{128}$ RPP 2010/2011
} 


\section{Future Fighter Capability Project}

Project Budget: $\$ 9$ billion

\section{Project Description:}

The objective of the Future Fighter Capability Project is to replace the CF-18 fleet upon its retirement. Canada initially joined the Concept Demonstration Phase of the Joint Strike Fighter Consortium in 1997, and subsequent phases of the project in 2002 and 2006. The 2008 Canada First Defence Strategy committed to purchasing "starting in 2017, 65 next-generation fighter aircraft to replace the existing fleet of CF-18s." 129 In June 2010 the Government of Canada announced that Canada would purchase the Joint Strike Fighter. ${ }^{130}$

\section{Explanation of Variance:}

In March 2011, the Parliamentary Budget Officer released a report indicating that the cost of acquiring the aircraft exceeded those released publically and in April 2012, a report from the Auditor General of Canada similarly presented a higher cost estimate and also indicated several problems with the process used to decide to purchase the F-35. On April 3, 2012, the Government of Canada announced a comprehensive response to Auditor General's report, including a Seven-Point Plan to address the Auditor General's recommendation. As a result, the National Fighter Procurement Secretariat was established to provide oversight and coordination amongst the departments involved with the implementation of the Seven-Point Plan, and the procurement was reset.

The RCAF has completed the evaluation of options, which has been reviewed by an Independent Review Panel, and all the associated work was completed in December 2014. While much of the supporting work that went into this process was made public, the conclusions of the review were not. It was reportedly presented to Government in the spring of 2014. ${ }^{131}$ At present, Canada remains in the Joint Strike Fighter Program to keep the F-35 option open and to provide companies in Canada the opportunity to compete for contracts on the F-35 aircraft. ${ }^{132}$ During the 2015 federal election, however, the Liberal Party of Canada stated that "We will not buy the F-35," and instead "immediately launch an open and transparent competition to replace the CF-18 fighter aircraft." 133 The Minister of National Defence's Mandate Letter instructs him to "launch an open and transparent competition to replace the CF-18 fighter aircraft, focusing on options that match Canada's defence needs."'134

\footnotetext{
129 Department of National Defence. Canada First Defence Strategy. 17.

130 Office of the Auditor General of Canada, 2012 Spring Report of the Auditor General of Canada: Chapter 2-Replacing Canada's Fighter Jets (Ottawa: Spring 2012)

131 Public Works and Government Services Canada, “National Fighter Procurement Secretariat (NFPS),” December 10, 2015 http:// www.tpsgc-pwgsc.gc.ca/app-acq/stamgp-lamsmp/snac-nfps-eng.html

132 RPP 2015/2016

133 Liberal Party of Canada, A New Plan for a Strong Middle Class (Ottawa: 2015), 70.

134 Prime Minister of Canada, Minister of National Defence Mandate Letter (Ottawa: 2015)
} 


\begin{tabular}{|c|c|c|c|}
\hline Major Milestones: & Initial $^{135}$ & $\mathbf{2 0 1 4}^{136}$ & Most Recent ${ }^{137}$ \\
\hline Identification Phase Approval & Jan 2010 & $\checkmark$ & \\
\hline First Procurement Request & Jan 2012 & & \\
\hline First Delivery & Dec 2016 & & \\
\hline $\mathrm{IOC}$ & May 2020 & & \\
\hline FOC & Sep 2025 & & \\
\hline Project Close Out & Dec 2027 & & \\
\hline
\end{tabular}

-In April 2012, a Complete Review of the Project was Announced-------------

$\begin{array}{lll}\text { Preliminary Project Approval } & 2015 / 2017 & 2015-2017 \\ \text { Effective Project Approval } & 2018 / 2020 & 2018-2020 \\ \text { Contract Award } & 2018 / 2020 & 2017-2019 \\ \text { First Delivery } & \text { TBD } & \text { TBD } \\ \text { IOC } & \text { TBD } & \text { TBD } \\ \text { FOC } & \text { TBD } & \text { TBD } \\ \text { Project Close Out } & \text { TBD } & \text { TBD }\end{array}$

Progress since September 2014:

None

\footnotetext{
135 DPR 2010/2011

136 DPR 2013/2014

137 RPP 2015/2016
} 


\section{Halifax Class Modernization/Frigate Life Extension}

\section{Project Budget: $\$ 4.3$ billion}

\section{Project Description:}

This project is both modernizing and life extending all 12 Halifax class frigates, commissioned between 1992 and 1996. It began as a life extension only (FELEX in the proceeding page), but this was combined in 2005 to include a number of capability upgrades (HCM/FELEX). This was pledged in the 2005 Defence Policy Statement ${ }^{138}$ and mentioned in the 2006 Conservative Party Platform. ${ }^{139}$ The ships were originally designed for anti-submarine warfare and antisurface warfare, in the open ocean environment, while the operational activities of the fleet have shifted increasingly to littoral regions. The project is providing enhancements to both sensors and weapons as well as life extending critical equipment. This includes: A new Combat Management System; radar suite; Interrogator Friend or Foe Mode S/5; internal communications system upgrade; harpoon Missile system upgrade; electronic warfare system upgrade; Long-range Infrared Search and Track system; modification to the gun; and replacement of the Shield II missile decoy countermeasures system, integrated machinery control system, and navigation radars. ${ }^{140}$ A limited capability to embark a Task Group commander has been added to four of the ships as well. ${ }^{141}$

\section{Explanation of Variance:}

The project is extremely complex, involving major changes the ships systems, with work occurring in two separate shipyards, with a separate contract for the Combat Systems Integration, Internal Communications System, and Weapons Control System. The project was led by an innovative management arrangement which created a Committee on Sponsors including the Assistant Deputy Minister Materiel, the Commander, RCN, the Assistant Deputy Minister Acquisitions from Public Works and Government Services Canada, as well as the Chief Executive Officers from each of the principal contractors to establish collaborative working relations from the beginning of the project. ${ }^{142}$ This arrangement was crucial to resolving schedule issues and controlling costs, and was facilitated by continuity in key staff positions. $^{143}$

\footnotetext{
138 Department of National Defence, Defence Policy Statement, 14.

139 Conservative Party of Canada, “Conservatives will boost defence on West Coast to protect Canadian sovereignty," December 27,2015 .

140 National Defence and the Canadian Armed Forces, "Halifax-Class Modernization (HCM) / Frigate Life Extension (FELEX)," November 24, 2014 http://www.forces.gc.ca/en/news/article.page?doc=halifax-class-modernization-hcm-frigate-life-extensionfelex/hkm9beb0

141 RPP 2015/2016

142 Chief Review Services. Audit of the Halifax-Class Modernization / Frigate Life Extension (HCM/FELEX) Project. (Ottawa: Department of National Defence, 2011)

143 Doug Dempster, "Navigating Complexity,” Vanguard, September/October 2015.
} 


$\begin{array}{llll}\text { Major Milestones: } & \text { Initial }^{144} & \mathbf{2 0 1 4}^{145} & \text { Actual }^{146} \\ \text { Preliminary Project Approval (FELEX) } & \text { Feb 2005 } & \checkmark & \\ \text { Preliminary Project Approval (HCM/FELEX) } & \text { Feb 2007 } & \checkmark & \\ \text { Effective Project Approval } & \text { Apr, 2008 } & \text { Sep 2008 } & \checkmark \\ \text { Multi-Ship Contract Awards } & \text { Oct 2007 } & \text { Mar 2008 } & \checkmark \\ \text { Combat System Integration Contract } & \text { Sep, 2008 } & \text { Nov 2008 } & \checkmark \\ \text { Refits Start } & \text { Apr 2010 } & \text { Oct 2010 } & \checkmark \\ \text { IOC } & & \text { Jan 2015 } & \text { Feb 2015 } \\ \text { FOC } & \text { Jan 2018 } & \text { Jan 2018 } & \text { Jan 2018 } \\ \text { Project Close Out } & \text { Apr 2018 } & \text { Jan 2019 } & \text { Jan 2019 }\end{array}$

\section{Progress Since September 2014:}

The first modernized frigates were delivered in late 2014 and the first upgraded frigate deployment occurred when HMCS Fredericton participated in Operation Reassurance from January to July 2015. It was replaced by HMCS Winnipeg, the second modernized frigate to deploy operationally. ${ }^{149}$ The final Halifax class frigates are currently in refit.

\footnotetext{
144 DPR 2006/2007

145 RPP 2014/15

146 RPP 2015/2016

147 RCN Subject Matter Expert, Email to the Author, November 2015

148 RPP 2009/2010

149 Government of Canada, "HMCS Winnipeg replaces HMCS Fredericton in support of NATO-led maritime assurance activities," July 7, 2015 http://news.gc.ca/web/article-en.do?nid=996859\&tp=1
} 


\section{Intelligence Surveillance, Target Acquisition and Reconnaissance}

\section{Project Budget: N/A}

\section{Project Description:}

This project is providing an integrated, interoperable, Intelligence Surveillance, Target Acquisition and Reconnaissance capability that will improve the ability of commanders to visualize the operational area, manage sensors and information collection resources, and to plan and implement actions to successfully complete operational missions. It will enhance existing capabilities and acquire new ones in the areas of communications, command and control and sensors. The project includes the acquisition of Unmanned Aerial Vehicles (UAV), Weapon Locating Sensors (WLS) and transformation or enhancement of existing sensor platforms to include Electronic Warfare (EW). In support of Operation Athena in 2003/2004 timeframe, the project delivered equipment in the areas of Command and Control, Tactical Unmanned Aerial Vehicles (TUAV), Weapons Locating Sensors and Electronic Warfare capabilities as 'Unforecasted Operational Requirements.' Early deliveries of elements of the Unmanned Aerial Vehicles, Electronic Warfare and Data Link Communications sub-projects continued during 2006 for Operation Archer. As well, urgently required systems, in particular the Acoustic Weapons Locating System, the Lightweight Counter Mortar Radar system, and additional Electronic Warfare systems were fielded in 2007.

\section{Explanations of Variances:}

Initial deliveries were estimated to occur in 2005-2006, but the Unforecasted Operational Requirement for an UAV and other sensor upgrades resulted in the delivery of a partial tactical UAV and Electronic Warfare capability in Afghanistan in 2003-2004. The implementation of the other sub-projects was delayed as the project team delivered numerous other aspects of the projects that were also Unforecasted Operational Requirements to Afghanistan. ${ }^{150}$ Current estimates are that the project will be completed in 2018. This delay is associated with the U.S. Government Contracting delays for equipment acquired through Foreign Military Sales and by other delays incurred in deliveries. ${ }^{151}$ The project benefited from the ability to make maximum use of its project management resources and reallocate project staff towards urgent requirements quickly as well as project management continuity. ${ }^{152}$

\footnotetext{
150 RPP 2014/2015

151 RPP 2015/2016

152 Doug Dempster, "Navigating Complexity,” Vanguard, September/October 2015
} 


$\begin{array}{llll}\text { Major Milestones: } & \text { Initial }^{153} & \mathbf{2 0 1 4}^{154} & \text { Most Recent }^{155} \\ \text { Preliminary Project Approval } & \text { April 3, 2003 } & \checkmark & \end{array}$

TUAV Unforecasted Operational Requirement (UOR)

Minister of National Defence Approval

May 2003

FOC

Dec 2005

Emergency Beyond Line of Sight Communication

Effective Project Approval

Nov 2005

FOC

Mar 2010

Communications \& Data Link Component

Effective Project Approval

Dec 2006

FOC

Dec 2013 Dec 2014

Command and Control (C2)

Effective Project Approval

Feb 2008

FOC

Jan $2014 \quad$ Nov 2015

Early Warning (EW) Sensors

Effective Project Approval

Nov 2005

FOC

Jan 2014 Jun 2015

In-Service Sensors Enhancement

Effective Project Approval

Jan 2012

FOC

Dec 2014 Mar 2016

Weapon Locating Sensors (WLS) Acoustic Sensor

Effective Project Approval

Nov 2005

FOC Apr 2010

Family of UAV

Effective Project Approval - UOR

Nov 2005

FOC

June 2015 Mar 2016

Light Weight Counter Mortar Radar

\footnotetext{
153 DPR2006/2007

154 RPP 2014/2015

155 RPP 2015/2016
} 
Effective Project Approval

FOC

Medium Range Radar

Effective Project Approval

IOC

FOC

Deliveries on All Sub-projects 2012

Project Close Out
Mar 2007

Dec 2014 Dec 2015

Jan 2012

Jan 2014 Mar 2015

Dec 2015 Mar 2016

Dec 2015 May 2018

Mar 2013

Dec $2016 \quad$ Sep 2018

\section{Notable Progress since September 2014:}

The Medium Range Radar contract was awarded to Rheinmetall Canada Inc. on July 27, 2015. ${ }^{156}$

156 Government of Canada, "Government of Canada Awards Contracts for Leading-edge Technology to Support Our Troops," July 27, 2015. http://news.gc.ca/web/article-en.do?nid=1007209 


\section{Joint Support Ship}

\section{Project Budget: $\$ 2.6$ billion}

\section{Project Description:}

This project is replacing the RCN's Auxiliary Oiler Replenishment vessels. It was first discussed in the 1994 White Paper, ${ }^{157}$ and the Liberal Party of Canada committed to purchase the vessels in their 2004 campaign, as did the Conservative Party of Canada in 2006. ${ }^{158}$ Early iterations of the project envisioned a vessel that would replace the existing capability and provide significant additional joint capabilities in the form of command and control, sealift and medical facilities. In August 2008, the project was cancelled when both submitted bids were "significantly over the established budget provisions." 159 The failure of this project and one for the Canadian Coast Guard, spurred the establishment of National Shipbuilding Procurement Strategy, which was launched June 3, 2010. ${ }^{160}$ A revised project received Treasury Board Preliminary Project Approval a week later. The project will see the ships based on an adaptation of the German Navy's Berlin Class, and will not provide significant joint capabilities.

\section{Progress Report and Explanations of Variances:}

The initial delay in acquiring this project was attributable to a shortage of capital funds in the 1990s. Subsequently the first iteration of the project failed due to a significant deterioration of the Government of Canada's knowledge of the Canadian shipbuilding industry, and the industry's condition by the mid-2000s. As with the other aspects of National Shipbuilding Procurement Strategy, this project was delayed by the overall National Shipbuilding Procurement Strategy. The Joint Support Ship project will be the third class of ship built at the Seaspan Vancouver Shipyards, following three Offshore Fisheries Science Vessels and then an Offshore Oceanographic Science Vessel for the Canadian Coast Guard. An agreement in principle for the construction of the first class was only reached and first steel cut in June 2015. Their production will take until 2017, to be followed by the second class, and only then will work start on the Joint Support Ship. While work is progressing on the vessels Initial Design Review, the project is impacted both by delays associated with the earlier projects that proceed it, and the resource intensive efforts to make progress on those same projects by both the shipyard and Canada. ${ }^{161}$ On June 23, 2015 the Government of Canada announced that it was pursuing an Interim Auxiliary Oiler Replenishment capability to be used until the Joint Support Ship is delivered.

157 Department of National Defence, 1994 White Paper. (Ottawa: 1994). http://www.forces.gc.ca/admpol/downloads/1994\%20White\%20Paper\%20on\%20Defence.pdf

158 Conservative Party of Canada, “Conservatives will boost defence on West Coast to protect Canadian sovereignty," December 27,2015

159 Government of Canada, "Archived - Bidders fail to meet budget requirements," August 22, 2008 http://news.gc.ca/web/article-eng.do?crtr.sj1D=\&mthd=tp\&crtr.mnthndVl=\&nid=416189

160 Public Works and Government Services Canada, "National Shipbuilding Procurement Secretariat,"

161 Royal Canadian Navy, Joint Support Ship, last modified June 10, 2015 http://www.navy-marine.forces.gc.ca/en/fleet-units/jss-home.page 


$\begin{array}{llll}\text { Major Milestones: } & \text { Initial }^{162} & \text { 2014 }^{163} & \text { Most Recent }^{164} \\ \text { Memorandum to Cabinet } & \text { Apr 2004 } & \checkmark \\ \text { Preliminary Project Approval } & \text { Nov 2004 } & \checkmark \\ \text { Project Definition Contract } & \text { Dec 2006 } & \checkmark \\ \text { Effective Project Approval } & 2008 & \checkmark \\ \text { First Delivery } & 2012 & \\ \text { IOC } & 2013 & \\ \text { FOC } & 2016 & \end{array}$

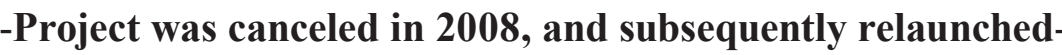

Revised Preliminary project Approval

Effective Project Approval

June $2010^{165}$

Implementation Contract

Feb $2013^{166}$

2016

2016

IOC

Mar $2013^{167}$

2016

2016

FOC

Spr $2018^{168}$

2019

$2021^{169}$

Project Close Out

Fall $2019^{170}$

2020

2020

2021

2020

\section{Notable progress Since September 2014:}

On October 27, 2014 a contract was awarded for the production of initial modules for the Offshore Fisheries Science Vessels, the first class of ships to be built at Seaspan shipyards.

This is the first step in testing the new shipyard processes implemented under the terms of the National Shipbuilding Procurement Strategy agreement. ${ }^{171}$ On June 12, 2015 an agreement in principle was announced for the construction and delivery of three Offshore Fisheries Science Vessels. ${ }^{172}$

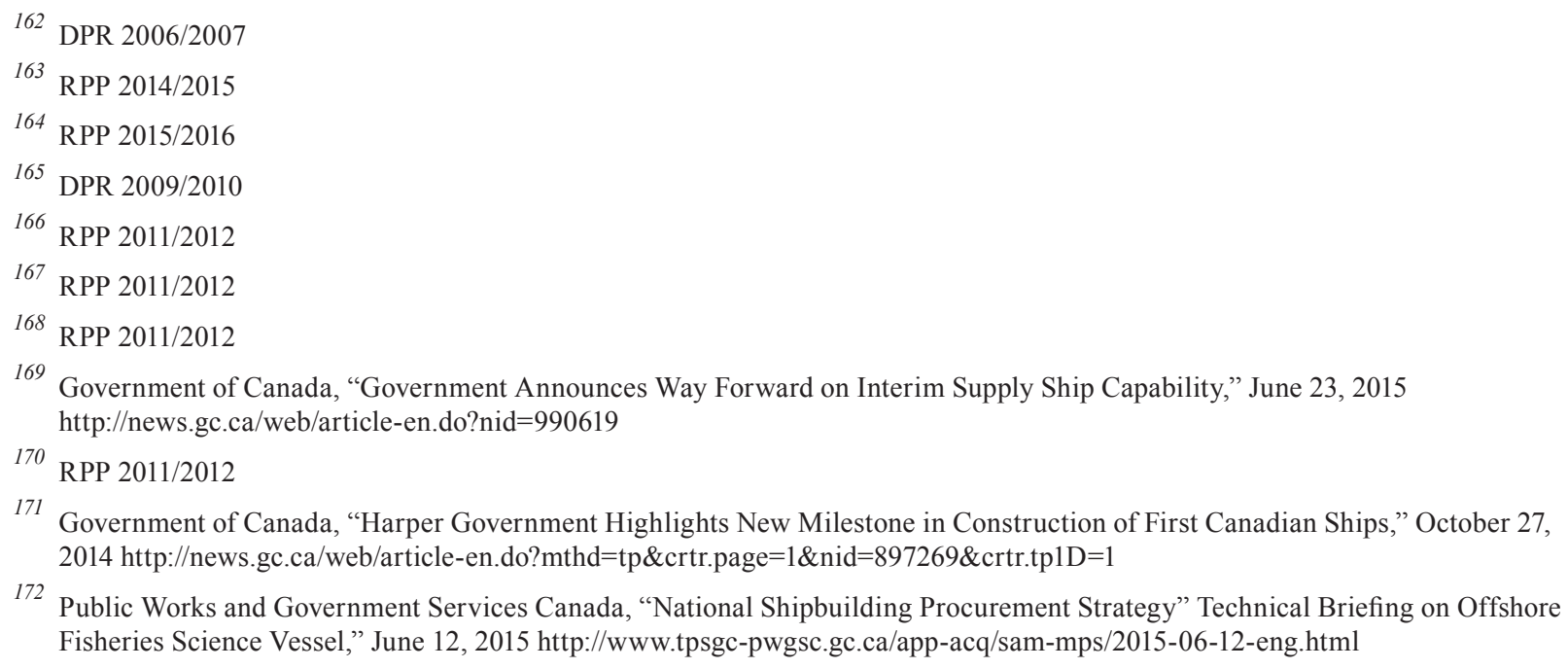
Fisheries Science Vessel,” June 12, 2015 http://www.tpsgc-pwgsc.gc.ca/app-acq/sam-mps/2015-06-12-eng.html 


\section{Joint Unmanned Surveillance and Target Acquisition}

\section{Project Budget: N/A}

\section{Project Description:}

The project was initially slated to procure and field a mature Medium Altitude Long Endurance Unmanned Aerial Vehicle system to provide capabilities for domestic and international operations. It was intended to complement existing reconnaissance, surveillance, and target acquisition capabilities, increase maritime and arctic domain awareness and provide a ground attack capability in support of Land and Special Operations Forces. ${ }^{173}$ The project now simply states that it will deliver a mature Long Endurance Unmanned Aircraft System capability that meets the objectives of the Canada First Defence Strategy for a robust domestic and international surveillance capability. This was mentioned in the 2006 Conservative Party of Canada platform, which committed to "Providing eastern and western Arctic air surveillance through stationing new long range uninhabited aerial vehicle (UAV) squadrons."174

\section{Explanation of Variance:}

The project has been in the Options Analysis stage since 2005. As a result of the limited market for unmanned aircraft that would satisfy all mandatory operational requirements in 2007, the project was delayed to enable a competitive procurement strategy, as a sole-source procurement was deemed unacceptable at the time by the contracting authority, resulting in a more than three year delay. In the meantime, the project office delivered a leased solution for operations in Afghanistan between 2009 and 2011, which delayed progress on the acquisition further. The project was again slowed down by changing capability requirements for speed, range, endurance, and intelligence functions. ${ }^{175}$

173 RPP 2011/2012

174 Conservative Party of Canada, “Stephen Harper stands up for Canada’s sovereignty in the Arctic," December 22, 2015.

175 Chief Review Services, Internal Audit of Joint Unmanned Surveillance and Target Acquisition System (JUSTAS) Project (Ottawa: Department of National Defence, March 2014) 


$\begin{array}{llll}\text { Major Milestones: } & \text { Initial }^{176} & \mathbf{2 0 1 4}^{177} & \text { Most Recent }^{178} \\ \text { Preliminary Project Approval } & \text { TBD } & 2016-2018 & 2017^{179} \\ \text { Effective Project Approval } & \text { TBD } & 2019-2020 & 2020^{180} \\ \text { Contract Award } & \text { TBD } & 2019-2020 & 2020^{181} \\ \text { First Delivery } & \text { TBD } & \text { TBD } & 2021-25 \\ \text { IOC } & \text { TBD } & \text { TBD } & \text { TBD } \\ \text { FOC } & \text { TBD } & \text { TBD } & \text { TBD } \\ \text { Project Close Out } & \text { TBD } & \text { TBD } & \text { TBD }\end{array}$

Significant Progress since 2014:

No Information Publicly Available.

\footnotetext{
$1762011 / 2012$

177 National Defence and the Canadian Armed Forces, Defence Acquisition Guide 2014

178 RPP 2015/2016

179 National Defence and the Canadian Armed Forces, Defence Acquisition Guide 2015

180 Ibid.

181 Ibid.
} 


\section{Light Armoured Vehicle III Upgrade Project}

Project Budget: $\$ 1.3$ billion

\section{Project Description:}

This project was part of the Family of Land Combat Vehicles Projects announced in the 2008 Canada First Defence Strategy. The CAF's experience in Afghanistan demonstrated the ongoing requirement for a highly protected, yet highly mobile Light Armoured Vehicle. The threats of mines, improvised explosive devises, explosively formed projectiles, and anti-armour weapons were deemed likely to be present in most medium to high threat missions. Despite improvements to the protection of the Light Armoured Vehicle (LAV) III fleet deployed to Afghanistan, it had insufficient armour to defeat modern threats, and insufficient mobility given the increased weight of the vehicle due to the protection kits and the increased stowage of combat supplies. Further, the target acquisition and fire control systems require upgrading to overcome obsolescence issues and to improve lethality. Contract award was announced in October 2011, and in November 2012 contract amendment was announced exercising an option to upgrade 66 additional vehicles for a reconnaissance and surveillance capability. ${ }^{182}$

\section{Explanation of Variance:}

First deliveries of the vehicles occurred in December 2012. Approximately 185 legacy LAV III have been inducted into production and 143 vehicles have been produced. The last public information indicates that 64 have been fielded to operational units. Initial Operational Capability occurred in June 2014. ${ }^{183}$

182 National Defence and the Canadian Armed Forces, “Light Armoured Vehicle (LAV) III Upgrade Project,” February 8, 2013 http://www.forces.gc.ca/en/news/article.page?doc=light-armoured-vehicle-lav-iii-upgrade-project/hie8w7nv

183 RPP 2015/2016 


$\begin{array}{llll}\text { Major Milestones: } & \text { Initial }^{184} & \mathbf{2 0 1 4}^{185} & \text { Most Recent }^{186} \\ \text { Preliminary Project Approval } & \text { June 2009 } & \checkmark & \\ \text { Contract Approval } & \text { Ear 2010 } & \checkmark & \\ \text { Implementation Start } & \text { Spr 2011 } & \text { Oct 2011 } & \checkmark \\ \text { First Delivery } & \text { Late 2011 } & \\ \text { IOC } & \text { Fall 2013 } & \text { End 2012 } & \checkmark \\ \text { FOC } & 2018 & \text { Spr 2014 } & \checkmark \\ \text { Project completed } & \text { Spr 2019 } & \text { Spr 2019 } & \text { Mar 2019 }\end{array}$

Significant Progress since Sept 2014:

No Information Publicly Available, but deliveries continue.

\footnotetext{
184 RPP 2010/2011

185 RPP 2014/2015

186 RPP 2015/2016

187 RPP 2010/2011

188 RPP 2013/2014
} 


\section{Lightweight Towed Howitzer}

\section{Project Budget: NA}

\section{Project Description:}

The Lightweight Towed Howitzer will bridge a key facet of the Army's current indirect fire capability deficiency. It will field twenty-five M777 lightweight $155 \mathrm{~mm}$ towed howitzers, each with a Digital Gun Management System (DGMS), supported by improved ammunition and a modern truck. These howitzers will augment the 12 M777 howitzers currently in-service. These capability enhancements in terms of lethality, range, precision, mobility and digitization are needed to support future missions and tasks likely to be assigned to the Canadian Army.

\section{Explanation of Variance:}

Deliveries of the M777 howitzers and the Digital Gun Management System components started in 2010 and were completed in the summer of 2011. IOC was originally forecasted to occur in July 2011 and was shifted to October 2011 as a result of unforeseen issues with technical integration. In October 2012, the project achieved full IOC. The M777 infrastructure initiative is currently in the construction phase. The majority of infrastructure initiatives are expected to be completed by 2015-2016.

The project is planning to achieve Effective Project Closure in March 2018, a delay from the original date of June 2016. This is due to the requirement to deliver infrastructure, the Medium Support Vehicle System gun tractor variant, ammunition components and the Ammunition Storage and Handling System before doing so. The project had significant interdependencies with the Medium Support Vehicle System project, which has been much delayed. In 2014/2015, the project was also informed that delivery of the improved ammunitions was delayed to address improvements after completion of the evaluation trial, delaying systems integration work until the ammunition is delivered. ${ }^{189}$

189 RPP 2015/2016 


$\begin{array}{llll}\text { Major Milestones: } & \text { Initial }^{190} & \text { 2014 }^{191} & \text { Most Recent }^{192} \\ \text { Preliminary Project Approval } & \text { Jan 2008 } & \checkmark & \\ \text { FMS Sales Agreement } & \text { Nov 2008 } & \checkmark & \\ \text { DGMS Contract Award } & \text { Apr 2009 } & \text { Nov 2009 } & \checkmark \\ \text { Effective Project Approval } & \text { June 2009 } & \text { Jan 2010 } & \checkmark \\ \text { IOC } & \text { Apr 2011 } & \text { Oct 2011 } & \text { Oct 2012 } \\ \text { FOC } & \text { Dec 2012 } & \text { Mar 2016 } & \text { Dec 2017 } \\ \text { Project Close Out } & \text { June 2013 } & \text { June 2016 } & \text { Mar 2018 }\end{array}$

Significant Progress since 2014:

No Information Publicly Available.

$\begin{array}{ll}190 & \text { RPP 2009/2010 } \\ 191 & \text { RPP 2014/2015 } \\ { }^{192} & \text { RPP 2015/2016 }\end{array}$ 


\section{Maritime Helicopter Project}

\section{Procurement Budget: $\$ 3.2$ billion}

\section{Project Description:}

This project was originally begun in 1986 under the New Shipborne Aircraft Project to acquire a fleet of Maritime helicopters. The latest iteration, the Maritime Helicopter Project, is scheduled to replace the fleet of $\mathrm{CH}-124$ Sea Kings with 28 new fully equipped Sikorsky Cyclone helicopters. The acquisition contract is bundled with a long-term in-service support contract and modify the modernized frigates discussed early to accommodate them. ${ }^{193}$

\section{Explanation of Variance:}

This project has been much delayed, beginning when the New Shipborne Aircraft Project was cancelled in 1993. When the project was re-launched, it was initially intended to award contracts separately for the Basic Vehicle and Integrated Mission System. The change in procurement strategy to letting a single contract for the Helicopter and its In-Service Support led to some early delay and was later abandoned. ${ }^{194}$ Since the Maritime Helicopter Project contract was signed in 2004, the project has experienced multiple further delays, largely related to the nature of the requirement. In 2008, after a request from the prime contractor, the contract was amended to allow for a delayed, tiered delivery schedule. This schedule was amended a second time in 2010. This was followed by a third party review and analysis of possible alternatives in 2013 to assess the feasibility of the project. ${ }^{195}$ While this was approved as an 'Off the Shelf' project, in reality it was not, as the helicopter that will ultimately be produced never existed before. This resulted in difficulties achieving the capabilities set out in the original contract, and required time consuming systems integration. Further, the incorrect assessment of the project's developmental nature resulted in an inappropriate management framework and project schedule. ${ }^{196}$

In June 2014, another contract amendment was signed extending the In-Service Support arrangements to 2038 at the original rates, and revised the project schedule, allowing for eight initial capability Block 1 Aircraft to be delivered starting in June 2015. To date, 27 helicopters have completed initial build, and four of these have completed the Block 1 upgrade program. The initial build of the 28th helicopter is underway. The project is running within its authorized budget. ${ }^{197}$

\footnotetext{
193 Plamandon, The Politics of Procurement

194 RPP 2001-2002

195 National Defence and the Canadian Armed Forces, “Archived - Maritime Helicopter Project: Status (Fact Sheet),”June 19, 2014 http://news.gc.ca/web/article-en.do?mthd=index\&crtr.page=1\&nid=859129

196 Office of the Auditor General of Canada. Chapter 6: Acquisition of Military Helicopters. (Ottawa: Minister of Public Works and Government Services Canada, 2010).

197 National Defence and the Canadian Armed Forces, "Archived - Maritime Helicopter Project: Status (Fact Sheet)"
} 


$\begin{array}{llll}\text { Major Milestones: } & \text { Initial } & \text { 2014 }^{198} & \text { Most Recent }^{199} \\ \text { Preliminary Project Approval } & \text { June 2003 } & \checkmark \\ \text { Invitation for Bids Posted } & \text { Dec 2003 } & \checkmark \\ \text { Effective Project Approval } & \text { Nov 2004 } & \checkmark\end{array}$

------The Project Schedule Was Revised Following a Contract Amendment in 2014----

Amended Project Approval June 2014

Contract Award

Nov 2004

First Delivery Jan 2009

(Interim) 2015

(Fully Capable)

$\begin{array}{lll} & 2018 & 2018 \\ 2013 & 2021 & 2022\end{array}$

Project Close Out

Significant Progress since Sept 2014:

On June 19, 2015 the first six, Block I Cyclones were accepted by the Government of Canada. ${ }^{200}$

198 RPP 2014/2015

199 RPP 2015/2016

200 Canada, Department of National Defence, “Canada accepts six CH-148 Cyclone Helicopters,” June 19, 2015.

http://news.gc.ca/web/article-en.do?nid=989279 


\section{Medium Support Vehicle System Project}

Project Budget: $\$ 1.1$ billion

\section{Project Description:}

On June 29, 2006 the Government of Canada announced that it would acquire medium sized logistics trucks as part of its Canada First Defence Strategy procurements. At the time of the announcement, this was articulated as the purchase of: 1500 vehicles designed for military use, up to 300 load-handling system companion trailers; 800 commercial vehicles adapted for military use; 1000 specially equipped vehicle kits, such as mobile kitchens, offices and medical or dental stations; and 300 armour protection systems. ${ }^{201}$ The Medium Support Vehicle System project was subsequently divided into five phases to reflect the aforementioned components, plus an additional fifth phase to provide for infrastructure. These are therefore: Phase 1: Militarized Commercial-Off-The-Shelf (MilCOTS); Phase 2 - Special Equipment Vehicle Baseline Shelters (Shelters); Phase 3 - Modification of the SEV Shelters (Kitting); and Phase 4 - Standard Military Pattern (SMP) Trucks. Contracts were awarded for the Shelters and Milcots phases in 2009 and for the Kitting in 2012. ${ }^{202}$

\section{Explanation of Variance:}

While most components of this acquisition progressed without problems, the Standard Military Pattern vehicle experienced greater difficulty. An RFP was released in 2011, but was ultimately cancelled just before the deadline in $2012 .{ }^{203}$ Over the time since it was originally launched, project requirements had evolved in lieu of the 2008 Canada First Defence Strategy and market factors had changed, as they had for a parallel Logistics Vehicle Modernization project which will also procure trucks for the army. Following a 2009 price and availability request to industry it was determined that additional funds were needed for the project, which were reallocated from the Logistics Vehicle Modernization project. While the total projects for each project combined remained unchanged, this financial reallocation was deemed to have not been properly communicated in official documentation. This was in part because of the introduction of the new reporting requirements related to the adoption of the Treasury Board's Invest Planning Policy, described earlier. This led to the Request for Proposal's cancellation, resulting in an 18 month project delay. ${ }^{204}$

\footnotetext{
201 Canada, National Defence, “Backgrounder: “Canada First” Defence Strategy Procurement, BG-06.014,” June 29, 2006.

202 RPP 2015/2016

203 The Canadian Press, "Military truck purchase cancelled due to cost concerns," July 11, 2012 http://www.cbc.ca/news/canada/military-truck-purchase-cancelled-due-to-cost-concerns-1.1273570

204 Canada, Department of National Defence, Chief Review Services. Internal Audit of the Medium Support Vehicle System Project. (Ottawa: Department of National Defence, 2014).
} 


\begin{tabular}{|c|c|c|c|}
\hline Major Milestones: & Initial $^{205}$ & $\mathbf{2 0 1 4}^{206}$ & Most Recent ${ }^{207}$ \\
\hline Preliminary Project Approval & June 2006 & $\checkmark$ & \\
\hline Effective Project Approval & June 2008 & $\checkmark$ & \\
\hline Invitation for Bids Posted (Milcots) & Aug 2007 & Nov 2007 & $\checkmark$ \\
\hline Contract Award (Milcots) & June 2008 & Jan 2009 & Jan 2009 \\
\hline First Delivery (Milcots) & Mar 2009 & June 2009 & $\checkmark$ \\
\hline Final Delivery (Milcots) & Sep 2010 & Oct 2012 & Mar 2011 \\
\hline Invitation for Bids Posted (Shelters) & Nov 2007 & May 2008 & $\checkmark$ \\
\hline Contract Award (Shelters) & June 2008 & July 2009 & $\checkmark$ \\
\hline First Delivery (Shelters) & July 2008 & Apr 2012 & May 2012 \\
\hline Final Delivery (Shelters) & June 2010 & 2014 & Feb 2015 \\
\hline Invitation for Bids Posted (Kitting) & & Oct 2011 & $\checkmark$ \\
\hline Contract Award (Kitting) & Dec 2012 & $\checkmark$ & \\
\hline First Delivery (Kitting) & & Fall 2013 & Jan 2014 \\
\hline Final Delivery (Kitting) & TBD & 2016 & Fall 2016 \\
\hline Invitation for Bids Posted (SMP) & Oct 2007 & July 2013 & $\checkmark$ \\
\hline Contract Award (SMP) & Nov 2008 & 2015 & Jun 2015 \\
\hline First Delivery (SMP) & Aug 2009 & 2017 & 2017 \\
\hline Final Delivery (SMP) & Aug 2011 & 2018 & 2018 \\
\hline IOC & 2013 & & \\
\hline FOC & 2016 & & \\
\hline Project Close Out & March 2010 & 2020 & 2020 \\
\hline
\end{tabular}

Notable Progress Since September 2014:

On July 16, 2015 the contract for SMP was awarded to Mack Defense. ${ }^{208}$

${ }^{205}$ DPR 2006/2007
${ }^{206}$ RPP 2014/2015
${ }^{207}$ RPP 2015/2016
${ }^{208}$ Government of Canada, “Government of Canada Awards Major Military Procurement Contracts for New Trucks,” July 16, 2015
http://news.gc.ca/web/article-en.do?nid=1001579 


\section{Medium-To Heavy-Lift Helicopter}

Project Budget: $\$ 2.3$ billion

\section{Project Description:}

The project has delivered 15 Chinook $\mathrm{CH}-147 \mathrm{~F}$ and is establishing a new transport helicopter capability to support land-based domestic and international operations. The project includes the associated infrastructure and support elements to create a new helicopter unit based at Garrison Petawawa. It was included in the 2005 Budget, and the 2005 Defence Policy Statement. It was first brought forward for Cabinet approval in the fall of 2005, but not approved. It was therefore delayed awaiting approval by the new Harper Cabinet after the 2006 election. ${ }^{209}$ As originally conceived, the project was to delivery its first helicopter in 2008, but this did not occur until $2013 .{ }^{210}$

\section{Explanation of Variance:}

The delays in acquiring the helicopter resulted from the evolution of the requirements after 2006, which were not finalized until a contract was signed in 2009. While the original requirements developed for the project could have been met by an existing model of the aircraft, the specifications actually provided to the contractor could not. They required significant changes to a basic helicopter model, requiring an additional two years to define the statement of work, and adding costs. This also impacted the timing and complexity of achieving certification for airworthiness. ${ }^{211}$

All 15 aircraft have been delivered, the last being accepted in June 2014. The most recent information, written in the fall of 2014, but not published until the spring of 2015, were that the project is progressively establishing the support systems and aircraft capabilities to enable the declaration of IOC in December 2014. A reduction in the size of the project office, commensurate with the work remaining, commenced in 2014 and will continue until project closure..$^{212}$

\footnotetext{
${ }^{209}$ Hillier, A Soldier First

210 Office of the Auditor General of Canada. Chapter 6: Acquisition of Military Helicopters. (Ottawa: Minister of Public Works and Government Services Canada, 2010).

211 Ibid.

${ }^{212}$ RPP 2015/2016
} 


$\begin{array}{llll}\text { Major Milestones: } & \text { Initial } & \mathbf{2 0 1 4}^{213} & \text { Most Recent }^{214} \\ \text { Preliminary Project Approval } & \text { June 2006 } & \checkmark & \\ \text { Advanced Contract Award Notice } & \text { July 2006 } & \checkmark & \\ \text { Effective Project Approval } & \text { Mar 2008 } & \text { June 2009 } & \checkmark \\ \text { Contract Award } & \text { Mar 2008 } & \text { June 2009 } & \checkmark \\ \text { First Delivery } & \text { Mar 2011 } & \text { June 2013 } & \checkmark \\ \text { IOC } & \text { Mar 2013 } & \text { June 2014 } & \text { Fall 2014 } \\ \text { FOC } & \text { Spr 2015 } & \text { June 2017 } & \text { June 2017 } \\ \text { Project Close Out } & \text { Fall 2015 } & \text { June 2018 } & \text { June 2018 }\end{array}$

Significant Progress since September 2014:

No Information Publicly Available.

$\begin{array}{ll}{ }^{213} & \text { RPP 2014/2015 } \\ 214 & \text { RPP 2015/2016 }\end{array}$ 


\section{Mercury Global}

\section{Project Budget: N/A}

\section{Project Description:}

The project will provide wideband global satellite communications that are guaranteed and directly interoperable with our principal allies. The project will deliver a Canadian Wideband Global System Military Satellite Communications System for near-worldwide assured, wideband communications to the Canadian military for the command and control of deployed Canadian commanders and forces, as well as interoperability with some of our principal allies, the United States, Australia, Denmark, the Netherlands, Luxembourg, and New Zealand.

\section{Progress Report and Explanations of Variances:}

In Phase 1, procurement of early access terminals and participation in the U.S. Department of Defense Wideband Global Satellite constellation was obtained through a 2012 Memorandum of Understanding for the construction and launch of the ninth Wideband Global System satellite. Effective Approval for Phase 2 was achieved in 2014 for the procurement and installation of the associated Wideband Global Satellite anchor station. The Effective Project Approval date was changed after consultation with Public Works and Government Services Canada who advised that the project seek Project Approval and Contract Authority simultaneously. Effective Approval for Phase 3, the strategic deployable terminals, will be sought in 2016 after the Definition stage of that project is completed. ${ }^{215}$

\section{Major Milestones:}

Preliminary Project Approval

Initial Satellite Access

Effective Project Approval

Terminal Implementation Complete

$\mathrm{IOC}$

FOC

Project Complete

$\begin{array}{lll}\text { Initial }^{216} & \mathbf{2 0 1 4}^{217} & \text { Most rece } \\ \text { Oct 2011 } & \checkmark & \\ \text { Nov 2011 } & \text { June 2012 } & \checkmark \\ \text { Jan 2014 } & \text { Apr 2014 } & \text { Oct 2014 } \\ \text { Oct 2016 } & \text { Oct 2016 } & \text { Oct 2016 } \\ & & \text { May 2013 } \\ \text { Oct 2017 } & \text { Oct 2017 } & \text { Oct 2016 } \\ \text { Win 2018 } & \text { Win 2017-18 } & \text { Jan 2017 }\end{array}$

\section{Notable Progress since September 2014:}

The project is currently in use, supporting Operation Impact. In November 2014 contracts were awarded to General Dynamics Canada for both the design and build and in-service support of the anchor stations. ${ }^{219}$

\footnotetext{
215 RPP 2015/2016

216 DPR 2011/2012

217 RPP 2014/2015

218 RPP 2015/2016

219 Government of Canada, "Department of National Defence Awards Contracts for the Mercury Global Project," November 12, $2014 \mathrm{http} / / /$ news.gc.ca/web/article-en.do?nid=903719
} 


\section{Protected Military Satellite Communications}

Project Budget: \$592 million

\section{Project Description:}

The Department of National Defence and the Canadian Forces require global communications that are secure, guaranteed and directly interoperable with our allies. The aim of the project is to overcome current Canadian interoperability and global command and control limitations. Upon completion, this project will enable long-range communications to deployed forces and facilitate their interoperability with allies.

\section{Explanations of Variances:}

In Phase 1, procurement of guaranteed access to the U.S. Department of Defense Advanced Extremely High Frequency satellite constellation was obtained through a Military Satellite Communications Memorandum of Understanding. Phase 2 has been underway since November 2003, when Effective Project Approval for the procurement and installation of the satellite terminals was granted. The Canadian project has been delayed by delays to the American satellite launch schedule and the Victoria Class submarine installation.

$\begin{array}{llll}\text { Major Milestones: } & \text { Initial }^{220} & \text { 2014 }^{221} & \text { Most Recent }^{222} \\ \text { Preliminary Project Approval } & \text { Aug 1999 } & \checkmark & \\ \text { Effective Project Approval } & \text { Nov 2003 } & \checkmark & \\ \text { Initial Terminal Delivery } & \text { Sum 2005 } & \text { Nov 2011 } & \checkmark \\ \text { IOC } & \text { Nov 2013223 } & \text { Nov 2013 } & \text { May 2013 } \\ \text { FOC } & \text { Fall 2017224 } & \text { Dec 2020 } & \text { Dec 2020 } \\ \text { Project Complete } & \text { Sum 2009 } & \text { Mar 2021 } & \text { Mar 2021 }\end{array}$

Notable Progress since September 2014:

No Information Publicly Available.

\footnotetext{
220 RPP 2000/2001, 58.

221 RPP 2014/2015

222 RPP 2015/2016

223 RPP 2014/2015

224 RPP 2011/2012
} 


\section{Submarine Capability Life Extension}

Project Budget: \$877 million

\section{Project Description:}

The Submarine Capability Life Extension project replaced the Oberon class submarine fleet with four existing British Upholder class (renamed Canadian Victoria class) submarines. The project will ensure that Canada preserves its submarine capability within the existing capital budget. The project supports Canada's ability to conduct surveillance and control of its territory, airspace and maritime areas of jurisdiction, as well as Canada's ability to participate in bilateral and multilateral operations.

The project delivered four functional Victoria class submarines with up-to-date, safe-to-dive certificates, four crew trainers (including a combat systems trainer, a ship control trainer, a machinery control trainer, and a torpedo handling and discharge trainer), and four trained crews.

\section{Explanation of Variance:}

Although Effective Project Closeout is expected in 2015/216, a small number of engineering changes still require installation in HMCS Corner Brook during her upcoming deep maintenance phase, as well as the procurement of long-lead supply items.

$\begin{array}{llll}\text { Major Milestones: } & \text { Initial }^{225} & \mathbf{2 0 1 4}^{226} & \text { Most Recent }^{227} \\ \text { Effective Project Approval } & \text { June 1998 } & \checkmark & \\ \text { Main Contract Award } & \text { Jul 1998 } & \checkmark & \\ \text { Initial Support Contract Award } & \text { Jul 1998 } & \checkmark \\ \text { IOC } & \text { Apr 2006 } & \\ \text { FOC } & \text { Dec 201128 } & \checkmark & \\ \text { Project Close Out } & \text { Mar 20132012 } & 2015 & \checkmark\end{array}$

Notable progress since September 2014:

Three of the boats are now in the "operational" phase of their life cycle: HMCS Windsor, Victoria, and Chicoutimi. ${ }^{231}$

\footnotetext{
225 RPP 1999/2000, 81.

${ }^{226}$ RPP 2014/2015

227 RPP 2015/2016

228 RPP 2009/2010

229 RPP 2009/2010

230 RPP 2009/2010

231 Royal Canadian Navy, "Victoria-class submarines reach operational steady state," February 26, 2015. http://www.navy-marine. forces.gc.ca/en/news-operations/news-view.page?doc=victoria-class-submarines-reach-operational-steady-state/i6miwqrg
} 


\section{Tactical Armoured Patrol Vehicle}

Project Budget: \$1.312 billion

\section{Project Description:}

The project will deliver to the Canadian Army a wheeled combat vehicle that will overcome deficiencies with the G-Wagon Light Utility Vehicle Wheeled, the RG-31 Armoured Patrol Vehicle, and the Coyote Light Armoured Vehicle related to capacity, protection, mobility, weapons effects, information and human dimensions. This vehicle will fulfill a wide variety of roles on the battlefield, including but not limited to surveillance, security, command and control, cargo and personnel carrier. It will have a high degree of tactical mobility and provide a very high degree of crew protection. The project scope includes an estimated initial purchase of 500 vehicles and an optional purchase of up to 100 more, plus associated long-term inservice support.

\section{Explanation of Variance:}

The project proceeded initially under an accelerated project schedule that compressed its Options Analysis stage by 10 months. As a result, the preliminary Statement of Operational Requirement, Concept Development and Experimentation and formal Price and Availability studies were delayed. Because of this, and the need to reengineer the available pre-existing vehicles to meet the requirement, the Definition stage was extended from 15 to 35 months. ${ }^{232}$

Following the contract award in June 2012, six pre-production vehicles were received in July 2013 for Qualification Testing at Canadian Forces Base Valcartier and at the United States Army Aberdeen Test Centre in Maryland. In August 2014 as part of this process, the first round of testing identified design problems. The project returned to the contract design phase in order to allow the complex, inter-related designs for the vehicle's structure, suspension and steering to be improved. Reliability testing resumed in the summer of 2015 and conclude by early 2016 . Repeat engineering qualification testing will be conducted as necessary. ${ }^{233}$

232 Chief Review Services. Internal Audit: Tactical Armoured Patrol Vehicle (TAPV). (Ottawa: Department of National Defence, 2011).

233 RPP 2015/2016 


$\begin{array}{llll}\text { Major Milestones: } & \text { Initial }^{234} & \text { 2014 }^{235} & \text { Most Recent }^{236} \\ \text { Identification Phase Approval } & \text { Mar 2008 } & \checkmark & \\ \text { Preliminary Project Approval } & \text { June 2009 } & \checkmark & \\ \text { Effective Project Approval } & \text { Sum 2011 } & \text { June 2012 } & \checkmark \\ \text { Contract Awarded } & \text { Fall 2011 } & \text { June 2012 } & \checkmark \\ \text { IOC } & 2013 & 2014 & \text { Mid-2016 } \\ \text { FOC } & 2015 & 2016 & \text { Mid-2017 } \\ \text { Project Complete } & 2017 & 2017 & 2017\end{array}$

Notable Progress since September 2014:

No Information Publicly Available, but since September 2014, the supplier has been engaged in a process of redesigning the vehicle.

\footnotetext{
234 DPR 2010/2011

235 RPP 2014/2015

236 RPP 2015/2016
} 


\section{Tank Replacement Project}

Project Budget: \$650 million

\section{Project Description:}

The purpose of the Tank Replacement Project is to replace Canada's aging Leopard C2 tank fleet with a modern, heavily protected, mobile, direct fire support capability. The Tank Replacement Project is broken into two phases. Phase 1 consists of the loan of 20 Leopard 2 A6M Main Battle Tanks, two Armoured Recovery Vehicles and logistics support from the German Government for immediate deployment to Afghanistan, as well as the purchase of up to 100 surplus Leopard 2 tanks from the Netherlands Government. Phase 2 will upgrade and introduce up to 100 Leopard 2 tanks and variants into service. ${ }^{237}$

\section{Progress Report and Explanations of Variances:}

Full FOC was changed from 2012 to an estimated date of February 2015 for several reasons. This includes the delivery of the Armoured Recovery Vehicles, schedule delay by Rheinmetall Canada (completed September 2014) and delivery of Phase 2 Initial Provisioning. All 42 Leopard 2A4 tanks and the first two Leopard 2 Armoured Recovery Vehicles have been delivered. All 20 Leopard 2 A4M tank have been delivered to date, two of them remain at the contractor, KMW, one as the reference tank and one undergoing upgrade work. The Leopard 2 A6M fleet, consisting of 20 tanks, continues to undergo a major repair program following the combat mission in Afghanistan. Currently, four Leopard 2A6Ms have completed repairs and have been returned to the Canadian Army. The project intends to achieve effective project closure, not Project Close Out, during May 2015 due to ongoing deliveries beyond this time from of Armoured Recovery Vehicles, Sub-Caliber Training Device and Initial Provisioning items. $^{238}$

\footnotetext{
237 RPP 2015/2016

${ }^{238}$ RPP 2015/2016
} 


$\begin{array}{llll}\text { Major Milestones: } & \text { Initial }^{239} & \mathbf{2 0 1 4}^{240} & \text { Most Recent }^{241} \\ \text { Memorandum to Cabinet } & \text { Mar 2007 } & \checkmark & \\ \text { Preliminary Project Approval } & \text { Mar 2007 } & \checkmark & \\ \text { Phase 1 MOU for German Loaners } & \text { May 2007 } & \checkmark & \\ \text { Phase 1 contract to upgrade Loaners } & \text { May 2007 } & \checkmark & \\ \text { Phase 1 IOC } & \text { Aug 2007 } & \checkmark & \\ \text { Phase 1 Acquisition of Dutch Tanks } & \text { Dec 2007 } & \checkmark & \\ \text { Effective Project Approval } & \text { Mid 2009 } & \checkmark & \checkmark \\ \text { FOC Phase 2 } & 2013+ & \text { Feb 2015 } & \checkmark \\ \text { Project Closed-Out } & 2013+ & \text { May 2015 } & \text { May 2015 }\end{array}$

Notable Progress since September 2014:

No Information Publicly Available.

\footnotetext{
239 DPR 07/08

${ }^{240}$ RPP 2014/2015

${ }^{241}$ RPP 2015/2016
} 


\section{ANNEX 2: DEFENCE ACQUISITION GUIDE 2015}

This section analyses the projects included in the Defence Acquisition Guide. This document was introduced as part of the Defence Procurement Strategy and is intended to "help Canadian industry position themselves to compete for potential future Canadian and international defence procurement opportunities." 242 Because the guide's intent is to provide information about future equipment needs for the military, most of the initiatives listed have not yet received Preliminary Project Approval and are therefore been subject to change or removal.

The 2015 edition of the Defence Acquisition Guide comprised 6 categories: Land Systems; Naval Systems; Aerospace Systems; Joint and Other Systems; Services; and Canadian Special Operations Forces Command Services. The analysis here concentrates only on the first three categories, denoted as Army, RCN and RCAF in the tables below. The later categories were excluded because the projects in those lists did not facilitate meaningful comparisons of capital equipment acquisitions. The Special Operations Forces category was new in 2015. The Services category contained only services. Further, the Joint and Other Systems contained projects from 12 different project sponsors within the CAF. Based on the initial analysis of the projects for the Army, RCN and RCAF, there were significant differences between the way each of those services (each a project sponsor) determined which projects to include in their entries in the document, and how precise they each were with respect to future milestone timelines. On that basis, the author determined that assessing the progress of the projects in the Joint and Other Systems category, proposed by 12 different sponsors, would not provide meaningful insights.

Of note, the Arctic Offshore Patrol Ship, Canadian Surface Combatant Project, Fixed Wing Search and Rescue Aircraft, Joint Support Ship, Joint Unmanned Surveillance and Target Acquisition and Future Fighter Projects are listed in the 2014 and 2015 Defence Acquisition Guides as well as DND's Status Report on Major Crown Projects. They therefore also appear in Annex 1. The Arctic Offshore Patrol Ship, Joint Unmanned Surveillance and Target Acquisition and Future Fighter Projects are On Time according to the metrics used in this Annex, which only compares progress year over year, even though their entries in Annex 1 demonstrate that all three projects are delayed relative to their original schedules.

Table 1 compiled data on the 2014 and 2015 entries for the Army, RCN and RCAF. The 2015 Defence Acquisition Guide entries that were new, had been archived, or had changed to absorb another project previously listed elsewhere on the 2014 edition of the document were excluded from this analysis. This excluded several Army projects that would otherwise by listed as 'Active' below, on the grounds that the changes to these projects resulting from combining them with others would preclude a meaningful analysis of their progress from one year to the next. ${ }^{243}$ Projects that were new, or had been archived could not be compared from year to year. It should be noted that some of the entries on the 2014 document were archived because the

\footnotetext{
242 National Defence and the Canadian Armed Forces, Defence Acquisition Guide 2015, June 25, 2014 http://www.forces.gc.ca/ en/business-defence-acquisition-guide-2015/naval-systems.page, National Defence and the Canadian Armed Forces, Defence Acquisition Guide 2014, June 25, 2014 http://www.forces.gc.ca/en/business-defence-acquisition-guide/joint-systems.page

243

The following 'active' projects were not analyzed because they had been combined or significantly altered between 2014 and 2015: Advanced Sub-Unit Water Purification System; Bridge and Gap Crossing Modernization; Camp Sustain; Common Heavy Equipment Replacement; and the Logistics Vehicle Modernization.
} 
projects advanced to the Implementation stage of their procurement. Canada signed onto the next phase of the Evolved Seasparrow Block 2, advancing the Point Missile Defence Upgrade project, ${ }^{244}$ a Request for Proposals for Fixed Wing Search and Rescue Aircraft was released in March 2015 and will close in January 2016, ${ }^{245}$ and Colt Canada will produce the New Canadian Ranger Rifle through the Munitions Supply Program, and was conducting testing this summer in the North. ${ }^{246}$

For the remaining entries, the project milestones in the 2014 Defence Acquisition Guide were compared with those for the 2015 iteration of the document. If all the milestones were the same, the project was counted as "On Schedule." If any of those milestones in the 2015 version were earlier than those in the 2014 Defence Acquisition Guide, the projects were counted as "Early," whereas if any of the milestones were later, they were counted as "Late."247

Overall, 117 projects were compared: 58 for the Army; 21 for the RCN; and 38 for the RCAF. Of these, 7 (6 per cent of the total) were Early, 42 (36 per cent of the total) were On Schedule, and 68 (58 per cent of the total) were Late. The breakdowns by service show that the projects for the Army, RCN and RCAF are all roughly similar in terms of their relative progress. The primary difference amongst them is that the RCN had one more Early project than either of the other two, out of a much smaller total number of projects.

Recognizing that the Defence Acquisition Guide is intended to provide an early indication of what projects the CAF might pursue in the future, a second analysis was conducted of only those projects that each of the services judged to be "Active," presented in Table 2. This restricted the analysis to those projects that actually had staff working on them, reducing the total number of projects examined to 59: 32 from the Army; 11 from the RCN; and 16 from the RCAF. Interestingly, the results of this analysis are almost exactly the same as those of the entire slate of projects: 3 per cent of the active projects are Early, 34 per cent are On Schedule and 63 per cent are Late. ${ }^{248}$ The full list of these projects is presented in Tables 5, 6 and 7 below.

Of note, this analysis shows that three of the RCN projects advanced from one stage of the procurement process to the next. The Arctic Offshore Patrol Ship project advanced from Definition to Contract Award and is now in Implementation, The Maritime Satellite Communications Upgrade received Effective Project Approval and the Naval Large Tug project moved into Options Analysis. Finally, although it occurred after the DAG was published, the Airspace Coordination Center Modernization, Royal Canadian Air Force Aerial Fire Fighting Vehicle, Search and Rescue Mission Management System Replacement and Underwater

\footnotetext{
244 Government of Canada, “Point Defence Missile System Upgrade: Evolved Seasparrow Missile Block 2,” December 192014. http://news.gc.ca/web/article-en.do?nid=916139

245 Public Works and Government Services Canada, "Fixed-Wing Search and Rescue Aircraft Replacement (FWSAR) Project," September 11, 2015 http://www.tpsgc-pwgsc.gc.ca/app-acq/stamgp-lamsmp/svtvn-rscfw-eng.html

246 Jody Porter, “Canadian Rangers test new 'top-tier weapon”” CBCnews.ca. July 10, 2015 http://www.cbc.ca/news/canada/thunder-bay/canadian-rangers-test-new-top-tier-weapon-1.3143122

247 One key difference between the 2014 DAG and the 2015 DAG is the latter provided more specific dates, rather than date ranges, for some projects. If the precise dates fell within a previous date range, it was counted to be On Schedule, if it fell earlier, Early, and later, Late.

248 This section and that in the Explanation of Variance, relied on interviews with Subject Matter Experts.
} 
Warfare Suite Upgrade projects received Preliminary Project Approval. ${ }^{249}$

TABLE 1 PROJECT SCHEDULE CHANGE FROM DAG 2014 - 2015

\begin{tabular}{|c|c|c|c|c|c|c|c|}
\hline \multirow{2}{*}{$\begin{array}{c}\text { Service } \\
\text { Army }\end{array}$} & \multirow{2}{*}{$\begin{array}{c}\text { Total } \\
58 \\
\end{array}$} & \multicolumn{2}{|c|}{ Faster } & \multicolumn{2}{|c|}{ On Schedule } & \multicolumn{2}{|c|}{ Slower } \\
\hline & & 2 & $3 \%$ & 20 & $34 \%$ & 36 & $62 \%$ \\
\hline $\mathrm{RCN}$ & 21 & 3 & $14 \%$ & 7 & $33 \%$ & 11 & $52 \%$ \\
\hline RCAF & 38 & 2 & $5 \%$ & 15 & $39 \%$ & 21 & $55 \%$ \\
\hline Total & 117 & 7 & $6 \%$ & 42 & $36 \%$ & 68 & $58 \%$ \\
\hline
\end{tabular}

TABLE 2 ACTIVE PROJECT SCHEDULE CHANGE FROM DAG 2014 - 2015

\begin{tabular}{|c|c|c|c|c|c|c|c|}
\hline Service & Total & \multicolumn{2}{|c|}{ Faster } & \multicolumn{2}{c|}{ On Schedule } & \multicolumn{2}{c|}{ Slower } \\
\hline Army & 31 & 0 & $0 \%$ & 11 & $35 \%$ & 20 & $65 \%$ \\
\hline Navy & 11 & 1 & $9 \%$ & 4 & $36 \%$ & 6 & $55 \%$ \\
\hline RCAF & 16 & 1 & $6 \%$ & 5 & $31 \%$ & 10 & $63 \%$ \\
\hline Total & $\mathbf{5 8}$ & $\mathbf{2}$ & $\mathbf{3 \%}$ & $\mathbf{2 0}$ & $\mathbf{3 4 \%}$ & $\mathbf{3 6}$ & $\mathbf{6 2 \%}$ \\
\hline
\end{tabular}

These projects were also categorized according to both their stage in the procurement process and their costs. The analysis of the projects according to the stage in the procurement process indicated that the same share of projects in the Identification (37 per cent), Options Analysis (38 per cent ) or Definition (38 per cent ) stages were Early or On Schedule (See Table 3 and Figure 1). Second, a greater share of the least and most expensive projects were Early or On Schedule: 67 per cent of the projects under $\$ 20$ million; 50 per cent of the projects between $\$ 500$ million and $\$ 1.5$ billion; and 43 per cent of the projects over $\$ 1.5$ billion (Table 4 and Figure 2).

TABLE 3 PROGRESS BY PROCUREMENT STAGE

\begin{tabular}{|c|c|}
\hline Project Phase & Early or On Schedule \\
\hline Identification & $37 \%$ \\
\hline Options Analysis & $38 \%$ \\
\hline Definition & $38 \%$ \\
\hline
\end{tabular}

TABLE 4

PROGRESS BY COST (\$M)

\begin{tabular}{|c|c|c|c|c|c|c|c|}
\hline Project Cost (\$M) & $<20$ & $20-49$ & $50-99$ & $100-249$ & $250-499$ & $500-1,500$ & $>1,500$ \\
\hline Early or On Schedule & $67 \%$ & $33 \%$ & $38 \%$ & $33 \%$ & $30 \%$ & $50 \%$ & $43 \%$ \\
\hline
\end{tabular}

${ }^{249}$ Interviews with RCAF and RCN Subject Matter Experts (Ottawa: 2015). 
FIGURE 1

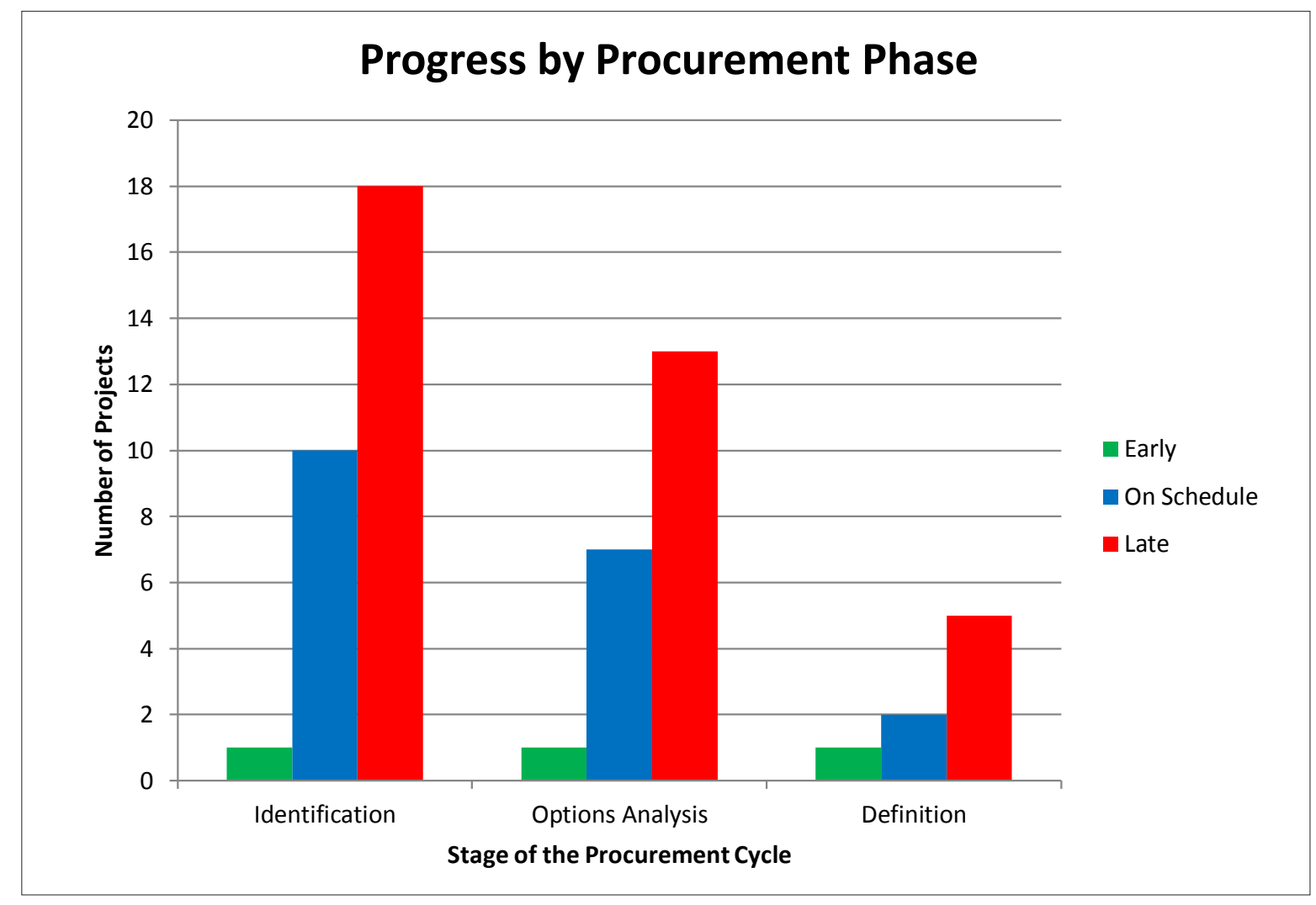

FIGURE 2

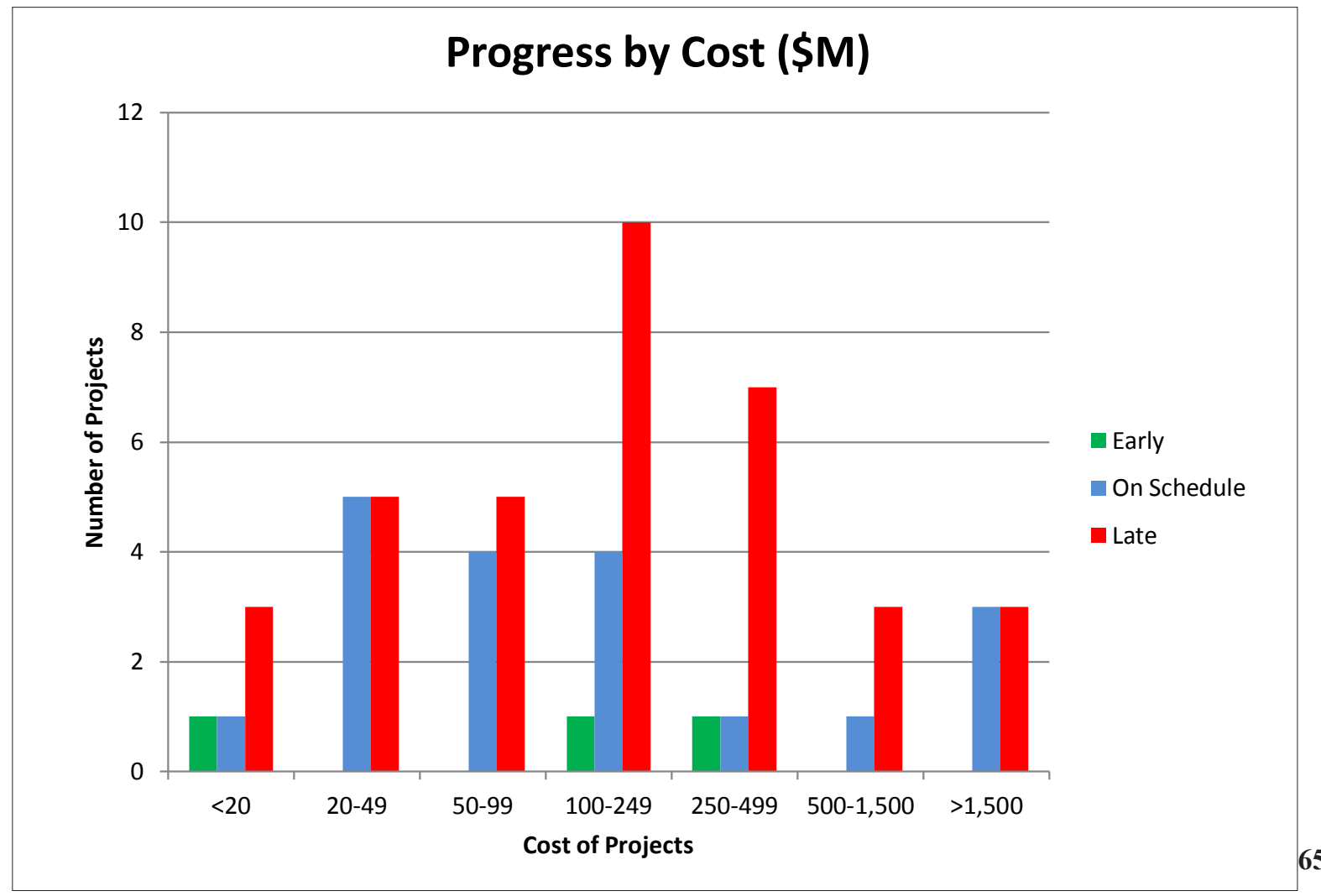




\section{EXPLANATION OF VARIANCE: 250}

The explanations provided for why the Early projects had advanced their milestones pointed to two different reasons. In one case, the project was part of a multi-national consortium, so Canada's procurement system needed to align with an external time pressure. In another instance, the project had spent so long in the Options Analysis stage that this facilitated a shorter than expected Definition stage.

Three primary issues have been cited as causes of delay for the Late projects. ${ }^{251} \mathrm{~A}$ lack of capacity was cited as a major impediment to progress, as the project sponsors in the Army, RCN and RCAF lack adequate staff to progress all their projects on their desired schedules. Even leaving aside the projects which have no staff assigned to them, some of the Late projects included in Table 2 were delayed because of a lack of adequate staff resources. A second significant issue was funding. Many other projects that are sponsor priorities are not included in DND's 2014 investment plan. As a result, they cannot receive Definition approval, and become funded projects, until the portfolio of projects identified for inclusion through the Capability Investment Plan Program Review are actually approved for inclusion in DND's Investment Plan. In some cases, they were on the secondary list of important projects identified through the Capability Investment Plan Program Review process, but are not part of the portfolio of projects identified for inclusion in the 2014 investment plan. A third source of delay is project interdependencies, particularly for the RCAF. A number of the RCAF's projects are related to management of Canada's existing fighter fleet and the acquisition of a future fighter. Their delay is therefore tied to progress on the future fighter project, which has made no progress since 2012 .

\footnotetext{
250 Confidential Interviews

251 The delays with those projects also listed in Annex 1 are not re-examined here.
} 
TABLE 5

ACTIVE ARMY PROJECTS

\begin{tabular}{|c|}
\hline 84mm Ammunition \\
\hline 84mm Carl Gustaf Upgrade \\
\hline Active Radio Frequencies Protection Systems \\
\hline Advanced IED Detection and Defeat \\
\hline Advanced Water Supply System \\
\hline Airspace Coordination Center Modernization \\
\hline Armoured Combat Support Vehicle \\
\hline C6 GPMG Modernization \\
\hline C16 Digital Compass Upgrade \\
\hline CF Land Electronic Warfare Modernization \\
\hline Close Combat Modular Fighting Rig \\
\hline Common Remote Weapon System \\
\hline Combined/Joint Intelligence Modernization \\
\hline Domestic and Arctic Mobility Enhancement \\
\hline Enhanced Recovery Capability \\
\hline FOO/FAC Modernization \\
\hline Ground Based Air and Munitions Defence \\
\hline High Risk Search Capability \\
\hline Indirect Fire Modernization \\
\hline Joint Deployable HQ and Signal Regiment Modernization \\
\hline Land Vehicles Crew Training System \\
\hline $\begin{array}{c}\text { LAV Operational Requirements Integration } \\
\text { Task Mobility Upgrade }\end{array}$ \\
\hline LAV OPV Crew Commander Independent Viewer \\
\hline $\begin{array}{l}\text { Land Command Support System Intelligence } \\
\text { Surveillance Reconnaisance Modernization }\end{array}$ \\
\hline $\begin{array}{l}\text { Land Command Support System Tactical Command } \\
\text { and Control Information System Modernization }\end{array}$ \\
\hline $\begin{array}{l}\text { Land Command Support System Tactical Communications } \\
\text { Modernization }\end{array}$ \\
\hline Light Utility Vehicle Wheeled Recapitalization \\
\hline RDX Replacement \\
\hline Small Arms Modernization \\
\hline Tactical Observer Fire Control System Upgrade \\
\hline Unit Weapons Training System \\
\hline Weapon Effects Simulation Mid Life Upgrade \\
\hline
\end{tabular}


TABLE 6 ACTIVE RCN PROJECTS

\begin{tabular}{|c|}
\hline Arctic/Offshore Patrol Ship \\
\hline Canadian Surface Combatant \\
Joint Support Ship \\
\hline Maritime Satellite Communications Upgrade \\
\hline Multi Role Boat \\
\hline Naval Large Tug \\
\hline Naval Remote Weapon Station \\
\hline RCN Intelligence Surveillance Tracking Acquisition \\
and Reconnaissance Programme \\
\hline StrongBow \\
\hline Submarine Equipment Life Extension \\
\hline Underwater Warfare Suite Upgrade \\
\hline
\end{tabular}

\section{TABLE 7 ACTIVE RCAF PROJECTS}

\begin{tabular}{|c|}
\hline $\begin{array}{c}\text { CFFTS Tactical Mission Training } \\
\text { System Replacement }\end{array}$ \\
\hline CC-130J Block 8 Upgrade \\
\hline CC-138 Twin Otter Life Extension Project \\
\hline CH-149 Cormorant Mid-Life Upgrade \\
\hline Future Fighter Capability \\
\hline Future Pilot Training \\
\hline Griffon Limited Life Extension \\
\hline Joint Unmanned Surveillance and \\
Target Acquisition System \\
\hline Medium Range Air-to-Air Missile Sustainment \\
\hline Omnibus Aviation Life Support \\
Equipment Modernization \\
\hline On-Scene Control Emergency \\
Response Modernization \\
\hline Royal Canadian Air Force Aerial \\
Fire Fighting Vehicle \\
\hline Royal Canadian Air Force Simulation \\
Implementation Project \\
\hline Search and Rescue Mission \\
Management System Replacement \\
\hline Tactical Integrated Command, Control \\
and Communications Air \\
\hline Weapon System Trainers \\
\hline
\end{tabular}

\begin{tabular}{|c|c|}
\hline \multicolumn{2}{|c|}{ Legend } \\
\hline & Early \\
\hline & On Schedule \\
\hline & Late \\
\hline
\end{tabular}




\section{ANNEX 3: GLOSSARY OF TERMS AND ACRONYMS}

Advance Contract Award Notice (ACAN): A public notice indicating to the supplier community the intent to award a contract to a pre-identified supplier, thereby allowing other suppliers to signal their interest in bidding, by submitting a statement of capabilities. If no supplier submits a statement of capabilities that meets the requirements set out in the ACAN, on or before the closing date stated in the ACAN, the contracting officer may then proceed with the award to the pre-identified supplier.

\section{Department of National Defence (DND)}

\section{Canadian Armed Forces (CAF)}

Effective Project Approval (EPA): Within National Defence, internal approval for the selected option and to proceed to the project's Implementation stage. Within the Treasury Board, expenditure authority to implement the project.

Full Operational Capability (FOC): The milestone reached when all project deliverables have been delivered

Initial Operational Capability (IOC): The milestone reached when the capability provided by the project can be used operationally on a sustained basis

In-Service Support (ISS): Activities required to sustain the operation of a military fleet over its lifetime, including engineering, training, inspection, maintenance and repair of equipment, and provision of spare parts.

Preliminary Project Approval (PPA): Within National Defence, internal approval in principle for the preferred option at the estimated cost and to proceed to the project's Definition stage. Within the Treasury Board, authorization to expend resources for the project's Definition stage.

Request for Proposal (RFP): A form of bid solicitation used when the bidder selection is based on best value rather than on price alone. Should be used when, owing to the nature of the requirement, suppliers are invited to propose a solution to a problem, requirement or objective, and the selection of the contractor is based on the effectiveness of the proposed solution.

Statement of Operational Requirement (SOR): A document stating characteristics that must be delivered for the project to satisfy the needed capability; contains the critical performance criteria necessary to evaluate technical options. 


\section{$\bowtie$ About the Author}

David Perry is the Senior Analyst and a Fellow with the Canadian Global Affairs Institute. He was previously the Senior Security and Defence Analyst of the Conference of Defence Associations Institute, where he authored multiple publications related to defence budgeting, transformation and procurement. He recently defended his doctoral dissertation in political science at Carleton University which examined the link between defence budgeting and defence procurement. 